\title{
Abordagem Diagnóstica e Terapêutica da Urticária Crónica Espontânea: Recomendações em Portugal
}

\author{
Diagnostic and Therapeutic Approach of Chronic \\ Spontaneous Urticaria: Recommendations in Portugal
}

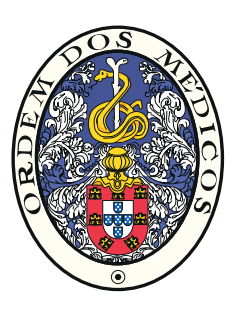

\author{
Célia COSTA $\triangle^{1,2}$, Margarida GONÇALO ${ }^{3,4}$ em nome do GPEU - Grupo Português de Estudos de Urticária \\ Outros colaboradores do artigo e membros do Grupo Português de Estudos de Urticária: \\ Pedro ANDRADE ${ }^{5}$, Filomena AZEVEDO ${ }^{6}$, Manuel Pereira BARBOSA ${ }^{7}$, Pedro Mendes BASTOS ${ }^{8}$, Rui Tavares BELLO ${ }^{9}$, \\ Ana TODO BOM ${ }^{10}$, Carmen BOTELHO ${ }^{11}$, Francisco Menezes BRANDÃO ${ }^{9}$, Ana BRASILEIRO ${ }^{8}$, Sofia CAMPINA ${ }^{2,12}$, \\ Ana Paula CUNHA ${ }^{6}$, Helena FALCÃO ${ }^{13}$, Emília FARIA ${ }^{10}$, José Alberto FERREIRA ${ }^{14}$, Paulo FILIPE ${ }^{7}$, João FONSECA ${ }^{15}$, \\ Leonor Cunha GRAÇA ${ }^{13}$, Arminda GUILHERME ${ }^{14}$, Martinha HENRIQUE ${ }^{16}$, Anabela LOPES ${ }^{7}$, Cristina LOPES ${ }^{17}$, Manuela LOUREIRO ${ }^{18}$, \\ Mário MIRANDA ${ }^{6}$, Marta NETO ${ }^{19}$, Elisa PEDRO ${ }^{7}$, Ana Margarida PEREIRA ${ }^{15}$, Celso PEREIRA ${ }^{10}$, Marta Isabel PEREIRA ${ }^{17}$, \\ Teresa PEREIRA ${ }^{11}$, Paula Leiria PINTO ${ }^{20}$, Leonor RAMOS ${ }^{10}$, Isabel ROSMANINHO ${ }^{14}$, Natacha SANTOS ${ }^{21}$, Pedro Morais SILVA ${ }^{21}$, \\ Ana SOKOLOVA ${ }^{22}$, João Teles de SOUSA ${ }^{12}$, Elza TOMAZ ${ }^{23}$, Ana Rita TRAVASSOS ${ }^{7,24}$, Paulo VARELA ${ }^{14}$, Glória Cunha VELHO ${ }^{13}$, \\ Jorge VIANA ${ }^{10}$
}

\section{Acta Med Port 2016 Nov;29(11):763-781 - http://dx.doi.org/10.20344/amp.8294}

\begin{abstract}
RESUMO
A urticária crónica espontânea é uma doença complexa, de etiologia mal-esclarecida, de diagnóstico fácil mas de abordagem terapêutica por vezes difícil. Tem um impacto significativo na qualidade de vida do doente e resulta em elevados custos diretos e indiretos. O diagnóstico da urticária crónica espontânea é essencialmente clínico, sendo recomendado um número limitado de exames complementares para diagnóstico diferencial e/ou para a investigação/exclusão de possível causa para a urticária crónica espontânea. Além do hemograma e da proteína C reativa, elou velocidade de sedimentação, os exames adicionais devem ser selecionados de acordo com critérios clínicos. O objetivo da terapêutica é o controlo clínico total da urticária crónica espontânea. A evolução deve ser documentada através do registo semanal do score de sintomas - Weekly Urticaria Activity Score (UAS7) -, assim como da avaliação de qualidade de vida. A abordagem terapêutica é baseada nos anti-histamínicos $\mathrm{H} 1$ (anti-H1) de segunda geração administrados de forma contínua nas doses aprovadas (primeira linha) e, na ausência de resposta clínica, até quatro vezes a dose diária aprovada (segunda linha). Os anti-H1 de primeira geração não são recomendados. Cerca de $30 \%$ dos doentes não ficam controlados com a terapêutica de segunda linha, pelo que é recomendado adicionar uma terapêutica de terceira linha. Das duas opções, omalizumab e ciclosporina, o omalizumab é a única opção com autorização de introdução no mercado para a urticária crónica espontânea, e possui melhor perfil de segurança, sendo assim recomendado preferencialmente. Em Portugal não existem recomendações nacionais aplicáveis à prática clínica. A elaboração destas recomendações é justificada pela necessidade de uniformização tanto da abordagem diagnóstica como da abordagem terapêutica dos doentes com urticária crónica espontânea em Portugal, e para a referenciação a centros especializados, nos casos mais graves.
\end{abstract}

Palavras-chave: Anti-histamínicos H1; Ciclosporina; Doença Crónica; Omalizumab; Urticária/diagnóstico; Urticária/tratamento.

1. Serviço de Imunoalergologia. Hospital de Santa Maria. Centro Hospitalar Lisboa Norte. Lisboa. Portugal.

2. Clínica Universitária de Imunoalergologia. Faculdade de Medicina. Universidade de Lisboa. Lisboa. Portugal.

3. Serviço de Dermatologia. Centro Hospitalar e Universitário de Coimbra. Coimbra. Portugal.

4. Clínica de Dermatologia. Faculdade de Medicina. Universidade de Coimbra. Coimbra. Portugal.

5. Hospital de Matosinhos. Matosinhos. Portugal.

6. Centro Hospitalar de São João. Porto. Portugal.

7. Hospital de Santa Maria. Centro Hospitalar de Lisboa Norte. Lisboa. Portugal.

8. Hospital dos Capuchos. Centro Hospitalar de Lisboa Central. Lisboa. Portugal.

9. Hospital dos Lusíadas. Lisboa. Portugal.

10. Centro Hospitalar e Universitário de Coimbra. Coimbra. Portugal.

11. Hospital de Braga. Braga. Portugal.

12. Hospital Egas Moniz. Lisboa. Portugal.

13. Hospital de Santo António. Centro Hospitalar do Porto. Porto. Portugal.

14. Centro Hospitalar de Gaia/Espinho. Vila Nova de Gaia. Portugal.

15. Hospital CUF Porto. Porto. Portugal.

16. Hospital de Santo André. Centro Hospitalar de Leiria. Leiria. Portugal.

17. Hospital Pedro Hispano. Matosinhos. Portugal.

18. Centro Hospitalar do Baixo Vouga. Aveiro. Portugal.

19. Hospital Pulido Valente. Centro Hospitalar de Lisboa Norte. Lisboa. Portugal.

20. Hospital D. Estefânia. Centro Hospitalar de Lisboa Central. Lisboa. Portugal.

21. Centro Hospitalar do Algarve. Portimão. Portugal.

22. Hospital Prof. Dr. Fernando da Fonseca. Amadora. Portugal.

23. Centro Hospitalar de Setúbal. Setúbal. Portugal.

24. Hospital CUF Descobertas. Lisboa. Portugal.

$\square$ Autor correspondente: Célia Costa. anaceliacosta@sapo.pt

Recebido: 11 de outubro de 2016 - Aceite: 25 de outubro de 2016 | Copyright @ Ordem dos Médicos 2016 


\section{ABSTRACT}

Chronic spontaneous urticaria is a complex disorder, of unclear etiology, easily diagnosed although often difficult to treat. It has a significant impact on the patients' quality of life and results in high direct and indirect costs. The diagnosis of chronic spontaneous urticaria is mainly clinical and a limited number of tests is recommended for differential diagnosis and/or for the investigation/exclusion of possible causes. In addition to the complete blood count and C-reactive protein, and/or erythrocyte sedimentation rate, additional tests must be selected according to clinical criteria. The aim of therapy is the complete clinical control of chronic spontaneous urticaria. Evolution should be documented by weekly symptom scoring - Weekly Urticaria Activity Score (UAS7) -, as well as the assessment of quality of life. The therapeutic approach is based on second-generation $\mathrm{H} 1$ antihistamines (anti-H1) administered continuously in the approved doses (first line), and, in the absence of a clinical response, up to four times the daily-approved dose (second line). First generation $\mathrm{H} 1$ antihistamines are not recommended. Approximately $30 \%$ of patients are not controlled with second line therapy, and it is recommended to add a third line therapy. Of the two options, omalizumab and cyclosporine, only omalizumab is approved for chronic spontaneous urticaria and has a better safety profile, thus being preferably recommended. In Portugal there are no national-based recommendations applicable to clinical practice. The elaboration of these recommendations is justified by the need to standardize both the diagnosis and the treatment approach of patients with chronic spontaneous urticaria in Portugal, and for the referral of patients to specialized centers, in the most severe cases.

Keywords: Chronic Disease; Histamine H1 Antagonists; Omalizumab; Practice Guidelines; Urticaria/diagnosis; Urticaria/therapy.

\section{INTRODUÇÃO}

A urticária crónica (UC), definida como o aparecimento de lesões cutâneas (máculo-pápulas eritematosas) e/ou angioedema durante um período superior a seis semanas, divide-se em dois grandes sub-grupos: a urticária crónica espontânea (UCE) e a urticária crónica indutível (UCInd). A UCE define-se como o desenvolvimento espontâneo de sintomas sem identificação de qualquer fator externo desencadeante, podendo existir causas conhecidas ou não. A UCInd possui diferentes agentes desencadeantes, que definem os vários tipos de UCInd: urticária ao frio, ao calor, de pressão, solar, aquagénica, colinérgica, de contacto, angioedema vibratório e dermografismo sintomático. ${ }^{1}$ As recomendações que se seguem dedicam-se exclusivamente à UCE, devendo, para os outros tipos de urticária, ser consultadas as recomendações internacionais e consensos de peritos existentes. ${ }^{1-7}$

Não existem dados específicos de Portugal, mas com base em estudos internacionais estima-se que a UC afete até $1 \%$ da população a qualquer dado momento, sendo que cerca de $2 / 3$ das UC são UCE. ${ }^{8-14}$ A UCE tem um impacto significativo na qualidade de vida $(\mathrm{QdV})$, resultando em elevados custos diretos e indiretos, nomeadamente com medicamentos, consultas médicas, idas aos serviços de urgência, hospitalizações, absenteísmo e presenteísmo. ${ }^{2} \mathrm{Em}$ Portugal, o custo médio de tratamento de um doente com UCE grave está estimado em $€ 6234 / 5$ anos, dos quais $€$ 4220 correspondem a custos diretos para o SNS e $€ 2004$ a custos indiretos, correspondendo a um custo médio anual de $€ 1244 /$ doente..$^{15}$ Muito importantes são ainda as implicações na vida diária do doente, nomeadamente as alterações de qualidade e quantidade do sono, com sonolência diurna e repercussão na capacidade de concentração, distorção da auto-imagem, isolamento social, alterações psicológicas e mesmo perturbações do humor, como a ansiedade e até depressão nos casos mais graves.

A UCE é uma doença complexa do ponto de vista fisiopatológico, multifatorial, o que dificulta a abordagem diagnóstica e terapêutica. Na literatura existe pouca evidência científica para recomendações em relação a procedimentos de diagnóstico ou terapêutica, com poucos trabalhos e casuísticas baixas, o que explica, pelo menos em parte, o sub-diagnóstico e sub-tratamento da UCE.
$\mathrm{Na}$ abordagem da UCE, a primeira dificuldade reside nas discrepâncias verificadas nas diversas recomendações internacionais em relação ao pedido de exames complementares de diagnóstico (ECDs), 1,2,-6, 16,17 baseado em escassa evidência científica. Após o diagnóstico, é consensual que o objectivo da terapêutica é o controlo total dos sintomas, ${ }^{1-4,6}$ avaliado pelo questionário Weekly Urticaria Activity Score (UAS7), ${ }^{1-3,16-18}$ de acordo com os valores apresentados na Tabela 1.19,20 Assim, um doente considera-se controlado se tem um UAS7 $\leq 6 .{ }^{3}$ Existe também o Urticaria Control Test (UCT), ainda não validado para a população Portuguesa. ${ }^{21}$ Paralelamente, é fundamental a regular avaliação da QdV dos doentes, nomeadamente com questionários como o Índice de Qualidade de Vida Dermatológico (DLQI), , ,17,22 e o Questionário de Qualidade de Vida para a Urticária Crónica (CU-Q2oL). ${ }^{1-3,5,16,17,22}$ Os valores do DLQI são também apresentados na Tabela 1..$^{19,23,24} \mathrm{O}$ CU-Q2oL está neste momento a ser validado para a população Portuguesa.

Quanto à abordagem terapêutica na UCE, é consensual que, numa primeira linha, devem ser utilizados anti-histamínicos $\mathrm{H} 1$ (anti-H1) de segunda geração nas doses aprovadas (on-label) ${ }^{1-6,16,17}$ Esta terapêutica de primeira linha deverá ser administrada continuamente até à resolução da UCE. ${ }^{1,17,25}$ Caso o controlo sintomático não seja alcançado, e como opção de segunda linha, poder-se-á aumentar a

\begin{tabular}{ll}
\multicolumn{2}{l}{ Tabela 1 - Valores de cut-off do UAS7 e DLQI } \\
\hline Valores UAS7 & Sintomas \\
\hline 0 & Sem sintomas \\
$1-6$ & Urticária controlada \\
$7-15$ & Urticária ligeira \\
$16-27$ & Urticária moderada \\
$28-42$ & Urticária grave \\
\hline Valores DLQI & Impacto na Qualidade de Vida \\
\hline $0-1$ & Não afeta a Qualidade de Vida \\
$2-5$ & Ligeiro \\
$6-10$ & Moderado \\
$11-20$ & Elevado \\
$21-30$ & Extremamente elevado \\
\hline
\end{tabular}


dose até quatro vezes a dose aprovada, ${ }^{1-5,16-18}$ ou substituir por outro anti-H1 de segunda geração, ${ }^{4,17}$ antes de avançar para terapêuticas de terceira linha. Os anti-histamínicos $\mathrm{H} 1$ de primeira geração já não são recomendados, devido aos seus efeitos adversos. ${ }^{1,3,17,25} \mathrm{Em}$ caso de necessidade de avançar para uma terceira linha há duas opções consensuais: o omalizumab e a ciclosporina. O omalizumab é a única opção de terceira linha com autorização de introdução no mercado (AIM) para a UCE a partir dos 12 anos de idade ${ }^{26}$ surgindo nas recomendações internacionais com recomendação forte. 1-4,6 Várias recomendações concordam que a ciclosporina A, utilizada off-label, ${ }^{27}$ é eficaz em combinação com um anti-H1 de segunda geração $0^{1,2,4,16,17}$; no entanto, esta deve ser utilizada com precaução devido aos seus efeitos adversos, ou indicada apenas em grupos específicos de doentes, , 1,3,4,16,17 com recomendação fraca na UC refratária às terapêuticas convencionais. ${ }^{6}$

Não existem recomendações nacionais aplicáveis à nossa prática clínica, mas cremos ser importante a sua existência, por forma a uniformizar a abordagem diagnóstica e terapêutica dos doentes com UC pelas diferentes especialidades às quais os doentes recorrem. Foram estas as razões que nos levaram à elaboração destas recomendações, que, sendo direcionadas à população portuguesa, adaptam as recomendações internacionais à realidade nacional. Estas recomendações são baseadas nos estudos e nas evidências clínica e científica existentes neste momento. Serão revistas a cada dois anos, de modo a incorporar novos conhecimentos na abordagem diagnóstica e terapêutica da UCE.

\section{MATERIAL E MÉTODOS}

Por iniciativa de vários imunoalergologistas e dermatologistas nacionais, foram contactados outros especialistas nestas duas áreas da medicina, que exercem clínica em centros nacionais, de Norte a Sul do País, especializados no seguimento e tratamento de doentes com urticária. Após uma reunião em setembro de 2015 , foi criado um grupo de trabalho que acordámos denominar-se de GPEU - Grupo Português de Estudos de Urticária. O GPEU, que conta atualmente com 43 membros, distribuídos de forma análoga pelas duas especialidades, recebeu o apoio científico das duas sociedades médicas que representam estas especialidades - Sociedade Portuguesa de Alergologia e Imunologia Clínica (SPAIC) e Sociedade Portuguesa de Dermatologia e Venereologia (SPDV). Na reunião inicial do GPEU foi discutido o interesse da adaptação das mais recentes recomendações europeias à realidade nacional, além de pontos atualmente polémicos no diagnóstico e tratamento do doente com UCE, na população em geral, e em populações especiais (crianças, grávidas/mulheres a amamentar, e idosos). Elaborámos uma lista com 12 perguntas

\section{Tabela 2 - Perguntas disponibilizadas na plataforma online}

1. Relativamente à investigação da urticária crónica espontânea (UCE), concorda que seja recomendada, por rotina e independentemente da história clínica do doente, a realização dos seguintes exames: hemograma, VS ou PCR?

2. Para a investigação da urticária crónica espontânea, de acordo com os critérios clínicos e/ou para diagnóstico diferencial, que exames complementares de diagnóstico recomenda?

3. Perante a ineficácia/efeitos adversos de um anti-histamínico $\mathrm{H} 1$ de segunda geração, recomenda a substituição por outro antihistamínico $\mathrm{H} 1$ de segunda geração?

4. Relativamente ao aumento de dose de anti-histamínicos $\mathrm{H} 1$ de segunda geração, concorda que seja recomendado o aumento de dose de um único anti-histamínico, de acordo com o respectivo perfil de segurança, em vez de se prescreverem combinações de diferentes anti-histamínicos?

5. Caso concorde que se faça substituição de anti-histamínicos H1 de segunda geração, por ineficácia/efeitos adversos concorda que esta substituição seja feita até três vezes, antes de passar para terapêutica de terceira linha?

6. Relativamente à reavaliação da necessidade de continuação/redução de terapêutica de segunda linha em doentes controlados (UAS7 $\leq 6)$, concorda que seja recomendada a sua realização até três meses após o início da terapêutica?

7. Relativamente à utilização do montelucaste no tratamento da UCE, cuja eficácia parece ser baixa, concorda que esta seja retirada do algoritmo terapêutico, mas mantida como opção adicional?

8. Relativamente ao tempo de espera para prescrever uma opção de terceira linha, concorda que sejam recomendadas pelo menos quatro semanas de tratamento de segunda linha?

9. Relativamente às duas opções de terceira linha, omalizumab e ciclosporina, concorda que a ciclosporina, dado o pior perfil risco/benefício, seja recomendada após ausência de resposta clínica ao omalizumab?

10. Relativamente à necessidade da reavaliação de continuação da terapêutica com omalizumab em doentes controlados (UAS7 $\leq 6)$, concorda que esta seja feita a cada 6 meses?

11. Relativamente à utilização de corticóides para o tratamento da UCE, concorda que estes sejam recomendados somente como tratamento de agudizações, num período máximo de 10 dias, e repetidos no máximo quatro vezes num ano?

12. Quais as indicações terapêuticas nas populações especiais? 
específicas em relação a cada um desses pontos - Tabela 2 - e respetivas opções de resposta e disponibilizámo-las numa plataforma online, de modo a que todos os elementos do GPEU pudessem votar na opção de resposta pretendida, com possibilidade de comentários adicionais.

Em janeiro de 2016, um especialista independente e que não pertence ao GPEU, fez uma revisão da literatura sobre urticária crónica, utilizando a base de dados MEDLINE. Os critérios de pesquisa no campo 'título' incluíram os seguintes termos: 'chronic urticaria' AND (idiopathic OR spontaneous OR diagnosis OR assessment OR severity OR quality of life OR qol OR treatment OR management OR special populations OR children OR pregnant), com limite de datas entre 01/01/2000 e 31/01/2016. Desta pesquisa resultaram 165 artigos científicos e recomendações, dos quais, com base na leitura dos resumos, selecionámos 121 pela sua relevância. Verificámos as referências bibliográficas destes 121 artigos e recomendações para identificar artigos adicionais e recomendações de interesse, e acrescentámos ainda a esta lista artigos existentes nas bases de dados de todos os elementos do GPEU. Disponibilizámos na plataforma online o texto integral desta lista final de 160 artigos e recomendações. Em final de fevereiro de 2016 o GPEU reuniu-se novamente para discutir e votar a resposta às perguntas colocadas na plataforma online. Nessa reunião, reformulámos e re-votámos algumas perguntas, sendo que considerámos consensual qualquer resposta com $\geq 75 \%$ dos votos - Tabela 3. Com base nos artigos previamente selecionados e disponibilizados na plataforma online, atribuímos a cada resposta um nível de evidência e grau de recomendação, de acordo com os Critérios de Oxford 28,29 - Fig. 1 e Apêndice 1 [http://www.actamedicaportuguesa. com/revista/index.php/amp/article/view/8294/8294_Apendice_01.pdf]. Acrescentámos ainda alguns artigos científicos relevantes referidos na reunião, sendo que um total de 192 artigos, recomendações e resumos das características do medicamento (RCM) constituíram a base científica destas recomendações.

Tabela 3 - Recomendações e resultados da votação

Recomendação

Resultado da votação

1. Recomendamos a realização de hemograma, VS ou PCR independentemente da história clínica do doente, para diagnóstico diferencial e exclusão de doença infecciosa ou inflamatória associada à UCE (LoE 3, GR D)

2. A exclusão de doenças infecciosas deve ser realizada de acordo com a história clínica e prevalência das doenças infecciosas em Portugal (LoE 5, GR D). Recomenda-se, ainda, com diferentes níveis de evidência e graus de recomendação, o doseamento de hormonas tiroideias e auto-anticorpos anti-tiroideus (LoE 3, GR C), a realização do ASST (LoE 3, GR D), e a pesquisa de ANA (LoE 4, GR D)

3. Dada a grande variabilidade na resposta individual a anti-H1 de segunda geração, os doentes podem beneficiar da substituição por outro anti-H1 de segunda geração (LoE 4, GR D)

4. O aumento de dose até quatro vezes a dose diária aprovada é preferível à combinação de diferentes antihistamínicos (LoE 3, GR D), desde que se mantenha um bom perfil de segurança. Os Níveis de Evidência e Graus de Recomendação para cada anti-H1 são os constantes da Tabela 4

5. A substituição até três vezes é suficiente para avaliar a resposta individual a anti-histamínicos $\mathrm{H} 1$ de segunda geração, pelo que após três tentativas dever-se-á avançar para terapêutica de terceira linha (LoE 5, GR D)

6. Nos doentes controlados com terapêutica de segunda linha, as doses de anti-H1 de segunda geração devem ser reavaliadas pelo menos até três meses após o seu início (LoE 5, GR D)

7. Apesar da segurança e baixo custo, dada a baixa eficácia do montelucaste, este deve ser retirado do algoritmo terapêutico, mas mantido como opção adicional associado à terapêutica de segunda linha (LoE 1, GR D)

8. Quatro semanas é o período de tempo considerado mínimo para avaliar a resposta a uma terapêutica de segunda linha e passar à terapêutica de terceira linha (LoE 5, GR D)

9. A ciclosporina é recomendada após ausência de resposta clínica ao omalizumab (LoE 1, GR A)

10. Os doentes em tratamento com omalizumab devem ser reavaliados pelo menos a cada seis meses (LoE 5, GR D)

11. Dado os reconhecidos efeitos adversos dos corticóides sistémicos a longo prazo, a sua utilização deverá ser reservada para o tratamento de agudizações, e durante o menor período de tempo possível (LoE 4, GR D)

12. Em populações especiais, apenas deverão ser utilizadas as indicações terapêuticas on-label, constantes da Tabela 4 (LoE 1, GR B). Poder-se-á considerar a utilização de terapêutica off-label, caso a caso, tendo em especial atenção o seu perfil de segurança (LoE 5, GR D)
$82,6 \%$

$87,0 \%$

$97,0 \%$

$77,0 \%$

$100,0 \%$

$85,0 \%$

$97,0 \%$

$84,0 \%$

$93,0 \%$

$100,0 \%$

$87,0 \%$ 
Níveis de Evidência e Graus de Recomendação para diagnóstico

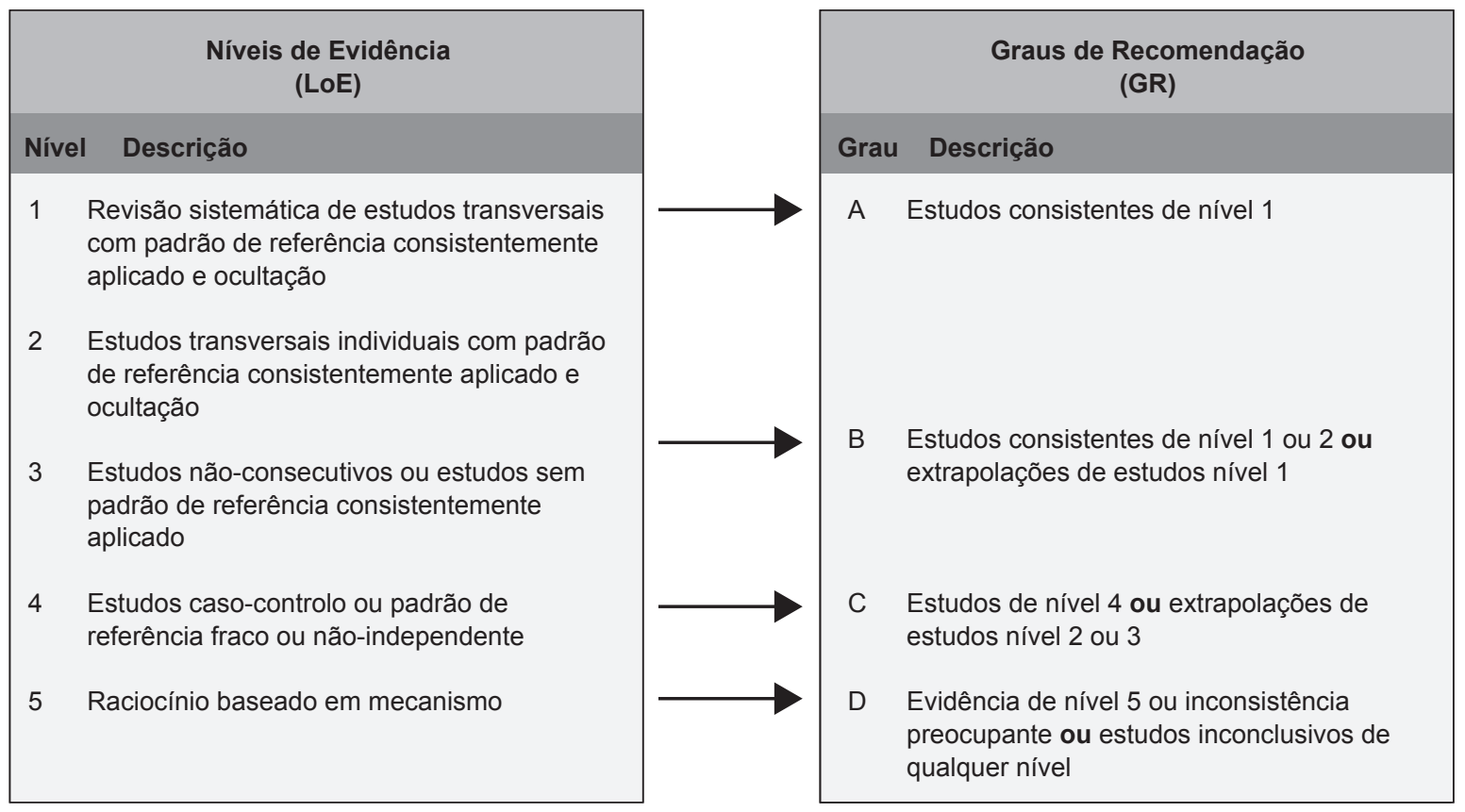

Níveis de Evidência e Graus de Recomendação para terapêutica

\begin{tabular}{|c|c|}
\hline $\begin{array}{c}\text { Níveis de Evidência } \\
\text { (LoE) }\end{array}$ & $\begin{array}{c}\text { Graus de Recomendação } \\
\text { (GR) }\end{array}$ \\
\hline Nível Descrição & Grau Descrição \\
\hline 1 Revisão sistemática de RTs ou n-de-1 ensaios & Estudos consistentes de nível 1 \\
\hline $\begin{array}{l}2 \text { RT ou estudo observacional com efeito } \\
\text { dramático }\end{array}$ & \\
\hline $\begin{array}{l}\text { Coortes não-aleatorizadas contoladas/estu- } \\
\text { dos de seguimento }\end{array}$ & $\begin{array}{l}\text { Estudos consistentes de nível } 1 \text { ou } 2 \text { ou } \\
\text { extrapolações de estudos nível } 1\end{array}$ \\
\hline $\begin{array}{l}\text { Séries de casos, estudos de caso-controlo ou } \\
\text { estudos historicamente controlados }\end{array}$ & $\begin{array}{l}\text { Estudos de nível } 4 \text { ou extrapolações de } \\
\text { estudos nível } 2 \text { ou } 3\end{array}$ \\
\hline Raciocínio baseado em mecanismo & $\begin{array}{l}\text { Evidência de nível } 5 \text { ou inconsistência } \\
\text { preocupante ou estudos inconclusivos de } \\
\text { qualquer nível }\end{array}$ \\
\hline
\end{tabular}

Figura 1 - Níveis de evidência e graus de recomendação, de acordo com os critérios de Oxford"28,29

\section{RESULTADOS E RECOMENDAÇÕES}

Pergunta 1: Relativamente à investigação da urticária crónica espontânea (UCE), concorda que seja recomendada, por rotina e independentemente da história clínica do doente, a realização dos seguintes exames: hemograma, velocidade de sedimentação (VS) ou proteína $\mathrm{C}$ reativa ( $\mathrm{PCR})$ ?

Em doentes com diagnóstico clínico de UCE, sem outras queixas clínicas, aos quais já foi realizada uma história clínica exaustiva e não foi identificada nenhuma causa subjacente, não é recomendada a realização de extensos testes diagnósticos. . $^{1,-6,16,17}$ No entanto, como primeira linha de investigação num doente com UCE, são recomendados alguns exames iniciais, nomeadamente para diagnóstico diferencial, ${ }^{4-6,16}$ que incluem hemograma, VS ou PCR. . $^{1,24-}$ 6,16,17 Contudo uma análise da evidência científica para esta recomendação, mostra que não existem ensaios clínicos aleatorizados e com ocultação (RCT) e os resultados dos diferentes estudos são inconsistentes.

Um estudo retrospetivo, que incluiu 750 doentes com 
urticária crónica refratária aos anti-histamínicos, não encontrou qualquer alteração nos valores do hemograma ou da VS nestes doentes, ${ }^{30}$ mas outra análise retrospetiva de 356 doentes com urticária crónica, com ou sem angioedema, concluiu que $34 \%$ dos doentes apresentavam hemograma com algum tipo de alteração. ${ }^{31}$ Os estudos reportam diferentes resultados nas alterações do hemograma em doentes com urticária crónica, nomeadamente aumento de leucócitos em $5 \%$ de 80 doentes, mas apenas nos doentes com teste de soro autólogo negativo, ${ }^{32}$ ou diminuição de linfócitos e basófilos em comparação com os controlos. ${ }^{33}$ $\mathrm{Na}$ realidade, foi encontrada uma associação positiva entre a atividade da doença e a basopénia, ${ }^{34}$ sendo esta basopénia mais grave em doentes com anticorpos anti-nucleares (ANA) positivos comparados com ANA negativos, ${ }^{35}$ e uma revisão recente confirma que alguns doentes com UCE têm basopénia. ${ }^{36} \mathrm{~A}$ eosinofilia foi reportada apenas nos doentes sintomáticos, ${ }^{37}$ estando presente em $12 \%$ de 50 doentes. ${ }^{38}$ Outro estudo de dimensão semelhante não encontrou diferenças nos valores de plaquetas entre doentes e controlos, ${ }^{39}$ mas tem sido referida trombocitose nos doentes com doença moderada a grave, ${ }^{40}$ e valores mais elevados de volume plaquetário médio e índice de dispersão plaquetária, ${ }^{41}$ ou valores mais elevados de volume plaquetário médio apenas em doentes com um teste de soro autólogo positivo. ${ }^{42}$

Um pequeno estudo concluiu que $6,3 \%$ de 80 doentes com urticária crónica apresentava VS elevada, ${ }^{32}$ e a PCR tem sido encontrada muito discretamente elevada em doentes com urticária crónica ${ }^{43,44}$ e com UCE, ${ }^{40,45}$ tendo sido sugerido que os níveis séricos de PCR podem ser um marcador de gravidade da urticária crónica em geral ${ }^{46}$ e da UCE. ${ }^{45,47}$ De facto, em doentes com urticária crónica, níveis elevados de PCR foram detetados em doentes com teste de soro autólogo positivo, ${ }^{42,46}$ que foi associado a maior gravidade da doença. ${ }^{42}$ No entanto, pelo menos um estudo não encontrou correlação entre os valores séricos da PCR e gravidade da urticária crónica ou aguda. ${ }^{48}$

Sabemos que as alterações do hemograma, VS ou PCR não são específicas da UCE, e que os resultados não são conclusivos quanto à relação das alterações encontradas e a gravidade da doença, mas na ausência de qualquer parâmetro laboratorial específico para a UCE, estes exames poderão ajudar no diagnóstico diferencial, nomeadamente para excluir doenças infecciosas ou inflamatórias crónicas que podem estar associadas à UCE, ou outras doenças, como as síndromes auto-inflamatórias, que podem cursar com lesões urticariformes semelhantes às da UCE.

Recomendação: Recomendamos a realização de hemograma, VS ou PCR independentemente da história clínica do doente, para diagnóstico diferencial e exclusão de doença infecciosa ou inflamatória associada à UCE (LoE 3, GR D).

Pergunta 2: Para a investigação da urticária crónica espontânea, de acordo com os critérios clínicos e/ou para diagnóstico diferencial, que exames complementares

\section{de diagnóstico recomenda?}

Pode ser necessária uma investigação mais exaustiva, recorrendo a ECD adicionais, que devem sempre ser baseados em critérios clínicos e guiados pela história clínica. A título de exemplo, estes ECD podem ser adequados em doentes com UCE grave e/ou de longa duração, ou resistente à terapêutica de primeira e segunda linha, por forma a identificar a existência de uma possível causa subjacente.

Vários ECD têm sido sugeridos e estão incorporados nas várias recomendações internacionais e consensos de especialistas. ${ }^{1,2,4-6,16,17}$ Referiremos aqui os que se nos afiguram mais pertinentes.

O teste de soro autólogo ou autologous serum skin test (ASST), teste intradérmico com o soro do próprio doente e de leitura imediata, tem sido usado para consubstanciar o envolvimento de mecanismos de auto-reactividade na UCE, numa altura em que não estão ainda disponíveis, na prática clínica diária, técnicas de doseamento de auto-anticorpos específicos. Na realidade, nos casos em que o ASST é positivo pressupõe-se a existência de uma substância desgranulante do mastócito em circulação, presumivelmente um anticorpo anti-recetor de alta afinidade da IgE (FceRI) e/ou anti-lgE da superfície dos mastócitos cutâneos e basófilos circulantes.

Este teste, largamente utilizado, tem sido questionado quanto à sua utilidade prognóstica no que diz respeito à gravidade e duração da doença, e, consequentemente, na abordagem terapêutica, ${ }^{49}$ mas poderá ser útil para oferecer ao doente a documentação de uma explicação provável para a sua UCE. Embora não existam RCT, diferentes estudos reportam percentagens de doentes com urticária crónica e ASST positivo entre 4,1\% a 76,5\%, ${ }^{32,44,49,50}$ com valores bastante variáveis na urticária crónica refratária à terapêutica ${ }^{51-53}$ e na UCE. ${ }^{38,54-57}$ Um estudo em Portugal mostrou que $58 \%$ dos doentes com UCE tinham ASST positivo, sendo que os doentes com ASST positivo e o teste de ativação dos basófilos também positivo apresentavam uma urticária mais grave e de maior duração. Este estudo também encontrou uma correlação significativa entre o ASST positivo e a presença de basopénia e de ANA. ${ }^{58}$

Por outro lado, resultados positivos de ASST têm sido descritos não só em indivíduos saudáveis, ${ }^{55,59}$ mas também em outras patologias, ${ }^{49}$ nomeadamente rinite alérgica, ${ }^{55}$ hipersensibilidade múltipla a anti-inflamatórios não-esteróides (AINES), ${ }^{60}$ e noutros tipos de urticária, nomeadamente colinérgica. ${ }^{59}$ Perante estes resultados, estes autores sugeriram que o ASST apresenta baixa especificidade e sensibilidade, ${ }^{55}$ e que são necessários mais estudos para avaliar a sua verdadeira utilidade. ${ }^{49}$ Paralelamente, pelo menos dois estudos sugerem que um ASST positivo está associado a maior gravidade clínica na urticária crónica,,2,61 mas a associação à presença de anticorpos anti-tiroideus ${ }^{38}$ continua controversa. ${ }^{49}$

A exclusão de doenças infecciosas, nomeadamente por Helicobacter pylori (H. pylori), e vírus da hepatite B ou C, também tem sido sugerida. No entanto, a evidência que sustenta uma associação entre estas infeções e a UC ou 
a UCE é contraditória. ${ }^{49,50,54,62-67}$ Da mesma forma, não é consensual que a erradicação do $H$. pylori resulte numa melhoria da UC.4,6,68,69 Para alguns autores, a decisão de erradicar o $H$. pylori deverá ser considerada no contexto da razão risco/benefício e tendo em conta a preferência do doente, ${ }^{69}$ enquanto outros consideram que o tratamento de erradicação do $H$. pylori é fácil e pode beneficiar os doentes com UCE mais grave, ${ }^{70}$ nomeadamente os resistentes às terapêuticas de primeira e segunda linha. ${ }^{71}$ Por outro lado, a prevalência destas infeções na UCE apresenta variações consideráveis consoante os estudos, de certa forma refletindo as diferenças regionais. ${ }^{1}$ Assim, recomendamos que a exclusão de doenças infecciosas deverá ser realizada de acordo com a história clínica, exames anteriores e prevalência em Portugal das respetivas doenças infecciosas, sabendo que, em 2013, esta era de $84,2 \%$ para H. pylori, ${ }^{72}$ e que, em 2015 , de $1,45 \%$ e $0,54 \%$ para a hepatite B e C, respetivamente, sendo mais elevada em grupos de risco. ${ }^{73}$

Quanto à pesquisa de ANA, anticorpos anti-tiroideus, e doseamento de hormonas tiroideias também há controvérsia, ${ }^{49}$ nomeadamente quanto à sua relevância clínica. ${ }^{6}$ A presença de ANA tem sido identificada em doentes com UC e UCE em percentagens que variam de $0,0 \%$ a $29,0 \%, 35,50,54,57,67,74-76$ mas também em indivíduos aparentemente saudáveis ou com outras patologias, em percentagens que variam entre $22,6 \%$ e $84,6 \%,{ }^{35,77,78}$ pelo que a sua presença não é necessariamente patogénica ${ }^{78}$ ou obrigatoriamente relacionada com a UCE. Os vários estudos que incluem doseamento de hormonas tiroideias e presença de auto-anticorpos anti-tiroideus reportam desde ausência de associação com a UC, ${ }^{75,79}$ até prevalências em doentes com UC ou UCE que variam entre $0,0 \%$ e $32,6 \%$. $40,50,54,57,61,74,76,80-85$ No entanto, em indivíduos considerados saudáveis a sua prevalência varia de $5,5 \%$ a $14,0 \% .^{80,81,84,86}$ Uma meta-análise recente, que incluiu um total de 14203 doentes com urticária e 12339 controlos sem urticária, concluiu que a prevalência de anticorpos anti-tiroideus era superior nos doentes com urticária, com OR entre 4,51 e 8,71, dependendo do anticorpo. ${ }^{87}$ Alguns estudos estabelecem associações entre a presença de ANA e uma UCE refratária a terapêuticas de primeira e segunda linha, ${ }^{35}$ entre a presença de ANA e a presença de anticorpos anti-tiroideus, ${ }^{57}$ e entre esta combinação e a gravidade da urticária. ${ }^{76} \mathrm{Um}$ estudo reporta que a duração da UC está associada à sua gravidade, presença de angioedema, ASST positivo e anticorpos anti-tiroideus. ${ }^{88}$ No entanto, o ASST e a presença de anticorpos anti-tiroideus não parecem ser preditores de resposta a ciclosporina, administrada após falência da terapêutica de primeira e segunda linha. ${ }^{89} \mathrm{~A}$ biópsia cutânea pode ser útil para distinguir a UCE de outras situações que cursam com lesões urticariformes, nomeadamente a vasculite urticariana e as síndromes auto-inflamatórias. ${ }^{90}$

Considerando a evidência acima, recomendamos, com diferentes níveis de evidência e graus de recomendação, os ECD abaixo mencionados, pois poderão ajudar no diagnóstico diferencial ou na identificação de patologia/ causa subjacente.
Não incluímos a recomendação Europeia ${ }^{1}$ para a dieta sem pseudo-alergéneos pois, para além da dificuldade em estabelecer com segurança uma tal dieta em Portugal, não parece ser muito relevante na prática clínica. O doseamento de auto-anticorpos funcionais (anti-recetor de alta afinidade da $\lg \mathrm{E}$ e/ou anti-lgE), que teria um potencial valor diagnóstico, ainda não está disponível.

Recomendação: A exclusão de doenças infecciosas deve ser realizada de acordo com a história clínica e prevalência das doenças infecciosas em Portugal (LoE 5, GR D). Recomenda-se, ainda, com diferentes níveis de evidência e graus de recomendação, o doseamento de hormonas tiroideias e auto-anticorpos anti-tiroideus (LoE 3, GR C), a realização do ASST (LoE 3, GR D), e a pesquisa de ANA (LoE 4, GR D).

Pergunta 3: Perante a ineficácia/efeitos adversos de um anti-histamínico $\mathrm{H} 1$ de segunda geração, recomenda a substituição por outro anti-histamínico H1 de segunda geração?

É consensual que existe uma grande variabilidade na resposta individual a anti-histamínicos $\mathrm{H} 1$ de segunda geração não-sedativos, não só em termos de eficácia mas também de tolerabilidade. 1,2,4,6,17,51,91,92 Assim, deverá ser oferecida a todos os doentes a oportunidade de mudar para outro anti-H1 de segunda geração, em caso de ineficácia ou devido a efeitos adversos. ${ }^{1,2,6,16-18,91,93}$ Dada esta variabilidade, e ao facto de os estudos existentes não permitirem concluir pela superioridade de qualquer anti-H1 de segunda geração sobre outro, ${ }^{4}$ não podemos recomendar nenhum anti-H1 de segunda geração específico como terapêutica inicial, em linha com as recomendações Europeias. ${ }^{4}$ Os estudos de substituição de um anti-H1 de segunda geração por outro anti-H1 de segunda geração são escassos, mas suportam esta variabilidade, e os potenciais benefícios da substituição. 51,67,92

Recomendação: Dada a grande variabilidade na resposta individual a anti-H1 de segunda geração, os doentes podem beneficiar da substituição por outro anti-H1 de segunda geração (LoE 4, GR D).

Pergunta 4: Relativamente ao aumento de dose de anti-histamínicos $\mathrm{H} 1$ de segunda geração, concorda que seja recomendado o aumento de dose de um único anti-histamínico, de acordo com o respectivo perfil de segurança, em vez de se prescreverem combinações de diferentes anti-histamínicos?

Começamos por salientar que os dados disponíveis de estudos de aumento de dose de anti-histamínicos $\mathrm{H} 1$ de segunda geração são limitados ${ }^{6,17,94}$ e contraditórios. . $^{6,94,95} \mathrm{~A}$ eficácia do aumento de dose parece depender do princípio ativo em causa, ${ }^{96}$ mas mesmo com o mesmo princípio ativo, os resultados de diferentes estudos são díspares. ${ }^{94,95}$ No entanto, considerando o bom perfil de segurança desta classe de medicamentos, as recomendações e consensos internacionais aconselham, como terapia de segunda linha, o seu aumento de dose até quatro vezes a dose aprova- 


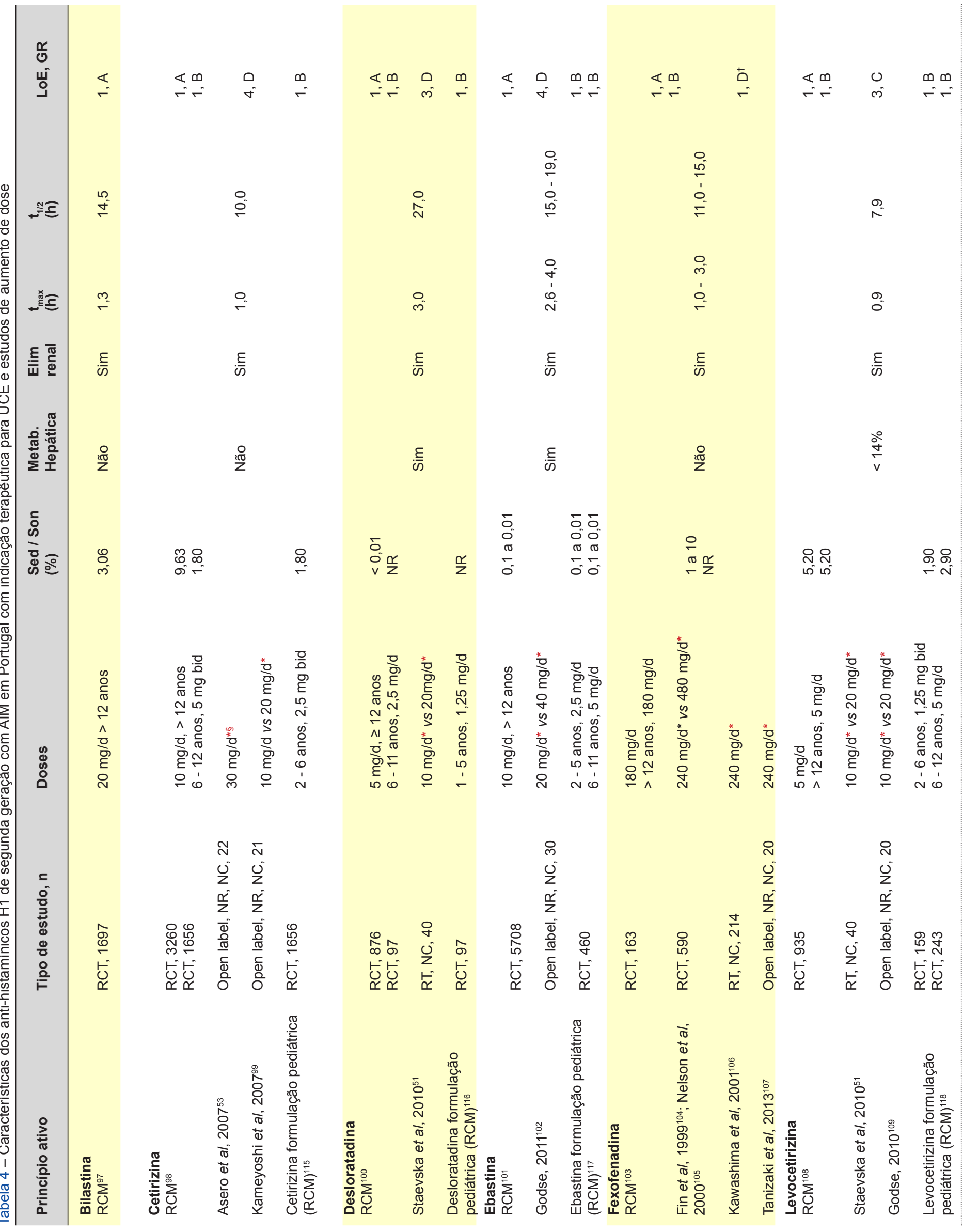




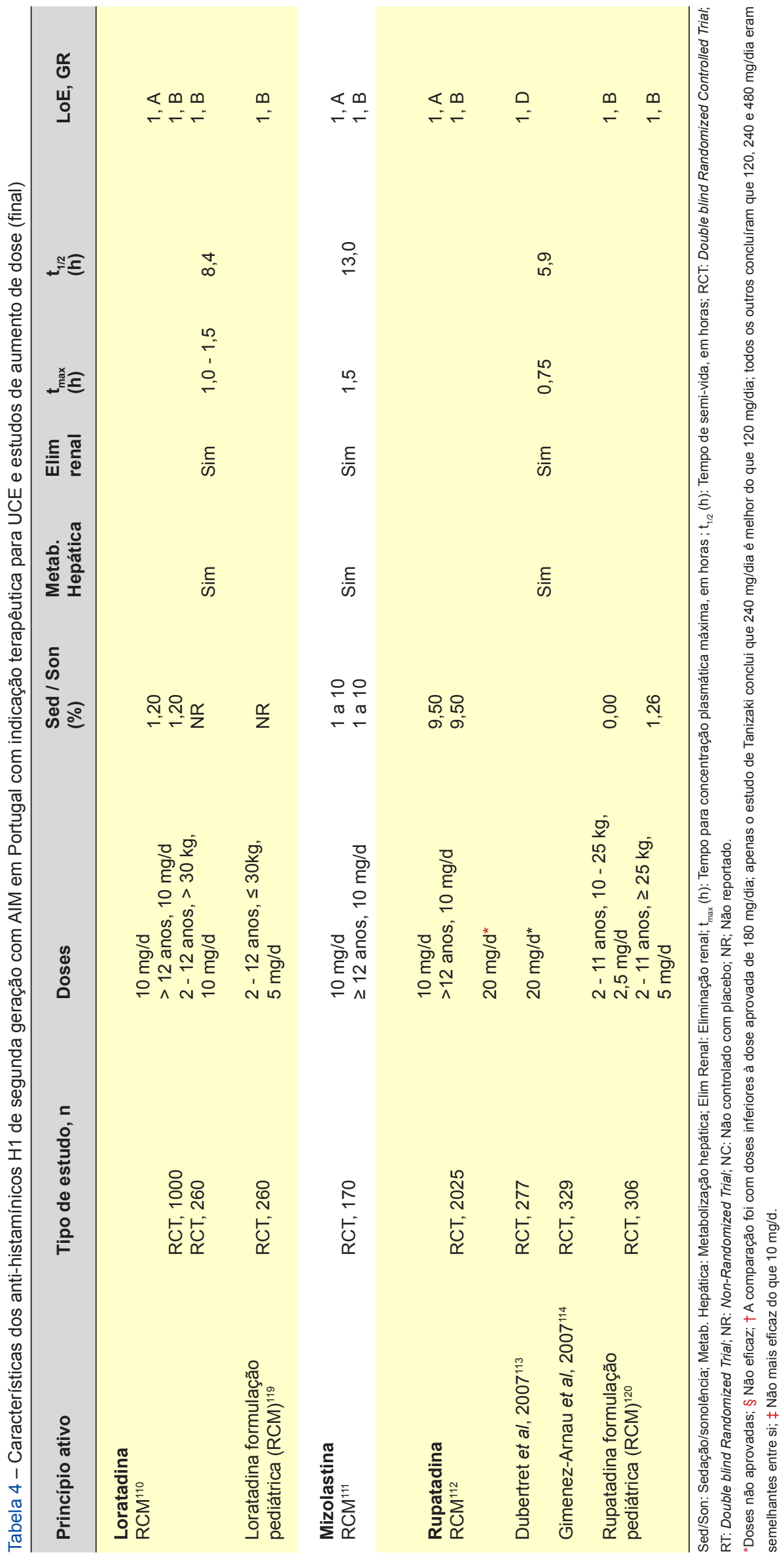


da, antes de avançar para terapêuticas de terceira linha, sempre tendo particular atenção aos potenciais efeitos adversos. ${ }^{1,2,4,5,16-18,91,94}$ Termeer et al alertam para os eventuais riscos deste aumento de dose, nomeadamente no que diz respeito aos potenciais efeitos sedativos de alguns anti-histamínicos $\mathrm{H} 1$ de segunda geração, que existem, embora em menor grau que os de primeira geração. No entanto, estes efeitos sedativos apresentam grande variabilidade individual e são dose-dependentes, tendo duração superior à da atividade anti-histamínica. ${ }^{16} \mathrm{~A}$ Tabela 4 apresenta os anti-histamínicos $\mathrm{H} 1$ de segunda geração atualmente com AIM em Portugal com indicação terapêutica para UCE, bem como todos os estudos de aumento de dose destes princípios ativos. ${ }^{51,53,97-120}$ Chamamos a atenção para o facto de que apenas as doses referidas no RCM têm indicação para a urticária (são on-label) sendo que todos os aumentos de dose não têm indicação para a urticária em RCM (são off-label). Dois estudos de vida real avaliaram a eficácia e segurança de aumento de dose de anti-histamínicos $\mathrm{H} 1$ de segunda geração. Num pequeno estudo de 85 doentes com UCE, $85 \%$ dos doentes a tomar anti-histamínicos $\mathrm{H} 1$ de segunda geração nas doses aprovadas mas não controlados, atingiram um bom controlo dos sintomas ao aumentar as doses. ${ }^{75}$ Num inquérito realizado a 319 indivíduos com diagnóstico clínico de UCE, $75 \%$ dos doentes reportaram que tinham aumentado a dose para dois, três, ou quatro comprimidos por dia, com efeitos benéficos em $40 \%, 42 \%$ e $54 \%$ dos casos, respetivamente, sem queixas de aumento de sedação. ${ }^{121}$

Embora não faça parte das recomendações europeias, poderá ser equacionada na terapêutica de segunda linha, como alternativa ao aumento de dose do anti-histamínico-H1 de segunda geração, a combinação de dois anti-histamínicos $\mathrm{H} 1$ de segunda geração, $, 17,122$ mas novamente alertamos para o risco envolvido, pois diferentes princípios ativos podem ter diferentes efeitos adversos em diferentes doentes, e a sua combinação pode aumentar estes mesmos efeitos adversos. ${ }^{122}$ No entanto, dados clínicos suportados por conhecimento dos efeitos farmacológicos de doses mais elevadas dos anti-H1 de segunda geração, sugerem que é preferível o aumento de dose do mesmo anti-H1 de segunda geração à combinação de anti-histamínicos. ${ }^{16,17}$ Os poucos estudos que há sobre combinações de anti-histamínicos em UCE concluem que não há diferença significativa no tempo necessário para controlar a doença entre a utilização de um ou múltiplos anti-histamínicos $\mathrm{H} 1,{ }^{67}$ nem existe vantagem em utilizar um anti-H1 de segunda geração de manhã e um de primeira geração à noite. ${ }^{123}$

Não há ordem estabelecida para a realização da substituição de anti-H1 de segunda geração na terapêutica de segunda linha, podendo ser feita antes de aumentar a dose do anti-H1 ou vice-versa. Propomos algumas opções, como por exemplo aumentar a dose para o dobro/fazer substituição/aumentar a dose para quatro vezes; fazer substituição/ aumentar a dose para o dobro/aumentar a dose para quatro vezes; aumentar a dose para o dobro/aumentar a dose para quatro vezes/fazer substituição. Não havendo evidên- cia para nenhuma das opções, todas são igualmente recomendadas (LoE 5, GR D).

Recomendação: 0 aumento de dose até 4 vezes a dose diária aprovada é preferível à combinação de diferentes anti-histamínicos (LoE 3, GR D), desde que se mantenha um bom perfil de segurança. Os níveis de evidência e graus de recomendação para cada anti-H1 são os constantes da Tabela 4.

Pergunta 5: Caso concorde que se faça substituição de anti-histamínicos $\mathrm{H} 1$ de segunda geração, por ineficácia/efeitos adversos, concorda que esta substituição seja feita até três vezes, antes de passar para terapêutica de terceira linha?

Não há evidência científica disponível sobre o número de vezes que se deve fazer a substituição. No entanto, alguns autores referem que a substituição pode ser feita mais do que uma vez, ${ }^{1,6,16,17,91}$ sem referir um número concreto. No entanto, não nos parece razoável oferecer todos os anti-histamínicos $\mathrm{H} 1$ de segunda geração disponíveis no mercado a um doente que mantém a sua urticária não controlada. Assim, a substituição até três vezes parece-nos razoável, do ponto de vista clínico, antes de avançar para a terapêutica de terceira linha.

Recomendação: A substituição até três vezes é suficiente para avaliar a resposta individual a anti-histamínicos $\mathrm{H} 1$ de segunda geração, pelo que após três tentativas dever-se-á avançar para terapêutica de terceira linha (LoE 5, GR D).

Pergunta 6: Relativamente à reavaliação da necessidade de continuação/redução de terapêutica de segunda linha em doentes controlados (UAS7 $\leq 6$ ), concorda que seja recomendada a sua realização até três meses após o início da terapêutica?

Apenas uma das recomendações europeias aconseIha reavaliar a necessidade de continuação do tratamento cada 3 - 6 meses, dado que não só a gravidade da urticária pode flutuar, como também pode ocorrer remissão espontânea a qualquer momento. ${ }^{1}$

É nossa opinião que, em doentes com UCE menos graves, controlados com terapêutica de segunda linha, deve ser feita uma reavaliação precoce da necessidade de continuação/ajuste do tratamento. Esta reavaliação permitirá decidir qual a abordagem terapêutica a seguir, possibilitando que em alguns doentes que estão completamente controlados a terapêutica seja reduzida, sem que haja perda de controlo. De salientar que, se for esta a opção terapêutica, a redução de dose deverá ser lenta, embora o método ótimo para esta redução não esteja determinado. ${ }^{6}$ Por outro lado, em caso de agravamento, haverá a possibilidade de aumentar a dose atempadamente. Também deveremos ter em consideração qual a terapêutica de segunda linha que o doente está a fazer. Para um doente com doses aprovadas ou duplas de anti-histamínicos $\mathrm{H} 1$ de segunda geração, controlado, três meses é um tempo razoável para a reavaliação, mas um doente com doses de quatro vezes 
a dose aprovada beneficiará de uma reavaliação antes de decorridos três meses da sua prescrição.

Gostaríamos apenas de referir que, tal como justificado na introdução, consideramos doentes controlados aqueles cujo UAS7 $\leq 6$.

Recomendação: Nos doentes controlados com terapêutica de segunda linha, as doses de anti-H1 de segunda geração devem ser reavaliadas pelo menos até três meses após o seu início (LoE 5, GR D).

Pergunta 7: Relativamente à utilização do montelucaste no tratamento da UCE, cuja eficácia parece ser baixa, concorda que esta seja retirada do algoritmo terapêutico, mas mantida como opção adicional?

As várias recomendações internacionais diferem nas recomendações de utilização do montelucaste no tratamento da UCE, havendo várias propostas, nomeadamente: como segunda linha terapêutica em associação, ${ }^{6}$ ou seja, sempre combinado com anti-histamínicos; como terceira linha em associação (com fraca recomendação) ${ }^{1}$; apenas após falha terapêutica do omalizumab ${ }^{16}$ (não recomendado) ${ }^{17}$; ou apenas em doentes seleccionados como segunda linha em associação, ${ }^{2}$ nomeadamente na urticária crónica auto-imune ou apenas com ASST positivo, urticária crónica associada a hipersensibilidade a aditivos alimentares ou AINES, ${ }^{4,91}$ e urticária crónica de pressão retardada. ${ }^{4}$ Esta inconsistência nas recomendações prende-se com o facto de haver muito poucos estudos RCT ou não-RCT com montelucaste, e os que existem terem casuísticas baixas e apresentarem resultados contraditórios.

Dois pequenos RCT em urticária crónica concluem que a combinação de desloratadina e montelucaste é eficaz no tratamento destes doentes, ${ }^{124}$ mas sem vantagem face à monoterapia com desloratadina na UCE moderada. ${ }^{125} \mathrm{Em}$ doentes refratários à terapêutica, a combinação de montelucaste com cetirizina parece ser eficaz e com um bom perfil de segurança. ${ }^{56}$

Três pequenos estudos não-RCT, todos em UCE refratária à terapêutica, concluem que o montelucaste, em associação, apenas diminuiu os sintomas numa minoria de doentes, ${ }^{126}$ mas se combinado com anti-H1 e anti-H2 parece ser uma terapêutica promissora. ${ }^{74,127}$ Um outro pequeno estudo tenta identificar subgrupos de doentes que possam beneficiar particularmente de montelucaste associado à terapêutica com anti-H1, sugerindo que este é eficaz em doentes mais jovens e com uma menor duração da doença. ${ }^{128}$ Três revisões sistemáticas de vários estudos RCT e não-RCT com antagonistas de recetores de leucotrienos (LTRA) têm conclusões diversas: 1) em doentes com urticária de etiologia desconhecida, sem hipersensibilidade à aspirina ou aditivos alimentares, ou com ASST negativo, a utilização de um LTRA em combinação com um anti-H1 não é superior na redução dos sintomas de urticária quando comparado com um anti-histamínico administrado em monoterapia ${ }^{129}$; 2) na urticária crónica os dados existentes são contraditórios, mas um LTRA associado a um anti-H1 (não como monoterapia) parece eficaz em doentes refractários a anti-histamínicos ${ }^{130}$; 3) na UCE, os LTRA não apresentam vantagens, nem como monoterapia, nem associados a anti-histamínicos. ${ }^{131}$

Sabemos, da experiência clínica, que uma reduzida percentagem de doentes responde ao montelucaste. Está também descrito, e deduz-se dos estudos acima mencionados, que essa resposta parece ser imprevisível. ${ }^{91}$ Assim, recomendamos que o montelucaste seja retirado do algoritmo terapêutico e mantido como opção adicional em associação a terapêutica de segunda linha.

Resta-nos salientar que a utilização do montelucaste no tratamento da urticária é off-label. ${ }^{132}$

Recomendação: Apesar da segurança e baixo custo, dada a baixa eficácia do montelucaste, este deve ser retirado do algoritmo terapêutico, mas mantido como opção adicional associado à terapêutica de segunda linha (LoE 1, GR D).

Pergunta 8: Relativamente ao tempo de espera para prescrever uma opção de terceira linha, concorda que sejam recomendadas pelo menos quatro semanas de tratamento de segunda linha?

As várias recomendações internacionais e estudos realizados referem que um doente é considerado refractário à terapêutica de segunda linha após três a 10 semanas consecutivas de terapêutica sem resultados satisfatórios no controlo da doença. ${ }^{1-3,71,75,122,133-137}$

É nossa opinião que, na maioria dos casos de UCE, 4 semanas será o tempo mínimo necessário para avaliar a resposta a terapêuticas de segunda linha. No entanto, salientamos que, se entendermos ser clinicamente mais favorável ao doente fazer a substituição de anti-H1 de segunda geração até três vezes, como recomendado acima, então este período deverá ser superior, pois o tempo de avaliação de eficácia de cada anti-H1 de segunda geração é de uma a duas semanas. Por outro lado, em casos de UCE mais grave, em doentes muito sintomáticos e não controlados, poderá ser necessário considerar terapêuticas de terceira linha antes de quatro semanas em terapêutica de segunda linha.

Recomendação: Quatro semanas é o período de tempo considerado mínimo para avaliar a resposta a uma terapêutica de segunda linha e passar à terapêutica de terceira linha (LoE 5, GR D).

Pergunta 9: Relativamente às duas opções de terceira linha, omalizumab e ciclosporina, concorda que a ciclosporina, dado o pior perfil risco/benefício, seja recomendada após ausência de resposta clínica ao omalizumab?

Várias recomendações concordam que a ciclosporina A, utilizada off-label, ${ }^{27}$ é eficaz em combinação com um anti-H1 de segunda geração. 1,2,4,16,17 No entanto, esta recomendação tem que ser cautelosa, dada a elevada incidência de efeitos adversos, nomeadamente hipertensão arterial, insuficiência renal e dislipidémia, que requerem avaliação clínico-laboratorial regular. Existe ainda a possibilidade de 
hirsutismo, imunossupressão e risco potencial de doenças malignas. $^{2-4,16,171}$ Ainda assim, a razão risco/benefício tem mostrado ser bastante superior à utilização de corticóides a longo prazo. 1,138 Dado o expectável aumento de efeitos adversos com o tempo de utilização, alguns autores recomendam este tratamento apenas por três meses, ${ }^{16}$ mas outros utilizam a ciclosporina em tratamentos mais longos, ${ }^{139-142}$ havendo mesmo recomendações para tratamentos prolongados quando necessário. ${ }^{143}$ As várias opções de recomendação descritas na literatura são: a) adição de ciclosporina a um anti-H1 de segunda geração, como opção de terceira linha, apenas em doentes com urticária grave e refratária a qualquer dose de anti-histamínicos ${ }^{1}$; b) apenas utilizar ciclosporina A após falha de resposta ao omalizumab ${ }^{16,17}$; ou c) considerar ciclosporina em baixa dose em doentes com urticária grave e refractária a anti-histamínicos. ${ }^{3,4}$ Uma das recomendações refere que, embora existam RCT que comprovam a eficácia da ciclosporina na UC e UCE, tanto administrada em monoterapia ${ }^{139,144}$ como em combinação com cetirizina, ${ }^{140}$ a qualidade destes RCT é baixa, com um grave risco de viés nos estudos de Grattan et a/ ${ }^{144}$ e Vena et al, ${ }^{140}$ e muito baixa, com um risco de viés muito grave, no estudo de Di Gioacchino et al. ${ }^{139}$ Assim, a recomendação para a utilização de ciclosporina na UC refratária a outras terapêuticas é fraca. ${ }^{6}$ Todas estas recomendações baseiam-se nos RCT acima mencionados e em vários pequenos estudos que mostram melhoria de sintomas em doentes com UC ou UCE refratária à terapêutica, com percentagens de eficácia de $39 \%$ a $78 \% .^{89,143,145-150}$ Estes estudos variam em doses e duração do tratamento, sendo a maioria de baixa dose (1 $3 \mathrm{mg} / \mathrm{kg} / \mathrm{dia}),{ }^{89,143,146,147}$ e as durações do tratamento entre um mês e 10 anos. ${ }^{143}$ No entanto, a resposta à ciclosporina é precoce, em quatro semanas, pelo que na ausência de melhoria clínica não existe aparente vantagem em prolongar o tratamento para além desse período. ${ }^{149}$

Embora para as doses mais elevadas de 4 - $5 \mathrm{mg} / \mathrm{kg} /$ dia, estejam reportados efeitos adversos em $20 \%$ a $30 \%$ dos casos, na sua maioria estes são transitórios ou meIhoram após diminuição de dose de ciclosporina A para 2 - $3 \mathrm{mg} / \mathrm{kg} / \mathrm{dia}$, sendo então reportada uma incidência mais baixa de efeitos adversos ${ }^{138}(7 \%$ a $35 \%),{ }^{89,143,146}$ e muito poucos casos com necessidade de descontinuação da terapêutica. ${ }^{138}$ Contudo, num estudo em doentes com UC muito grave medicados com $3 \mathrm{mg} / \mathrm{kg} / \mathrm{dia}$ de ciclosporina, $20 \%$ tiveram que descontinuar a terapêutica nos primeiros 2 - 15 dias devido a efeitos adversos. ${ }^{143}$ Por outro lado, um estudo com dose de $4 \mathrm{mg} / \mathrm{kg} /$ dia afirma que não houve efeitos adversos. ${ }^{148}$

O omalizumab é a única opção de terceira linha com AIM para a UCE a partir dos 12 anos de idade,${ }^{26}$ constando nas recomendações internacionais com recomendação forte, ${ }^{1,6}$ de grau $A,{ }^{4}$ por ser a terapêutica com o mais elevado nível de evidência, tanto de eficácia como de segurança. ${ }^{2,3}$ Uma meta-análise recente, que utilizou a avaliação GRADE, incluiu 5 RCT de omalizumab, com três estudos de fase III - ASTERIA I, ${ }^{136}$ ASTERIA II ${ }^{133}$ e GLACIAL ${ }^{135}$ - e dois de fase II - MYSTIQUE ${ }^{137}$ e X-QUISITE, ${ }^{134}$ com um total de 1116 participantes. Todos os RCT foram considerados como tendo um baixo risco de viés. Nos grupos tratados com omalizumab houve melhoria significativa na atividade da doença e na qualidade de vida dos doentes, quando comparados com os grupos medicados com placebo, havendo diferenças médias de $-11,58$ no UAS7 e de $-13,12$ no DLQI. Os doentes tratados com omalizumab também apresentaram respostas totais ou parciais significativamente mais frequentes, com razões de risco (risk ratio) de 6,44 e 4,08, respetivamente. Quanto ao perfil de segurança, não houve diferença significativa de doentes a reportar efeitos adversos entre os grupos omalizumab e os grupos placebo. Os autores concluem que o nível de evidência que suporta a eficácia e segurança de omalizumab, na dose de $300 \mathrm{mg}$ de quatro em quatro semanas para o tratamento da UCE até seis meses, é de elevada qualidade. ${ }^{151}$ Vários outros estudos de menor dimensão, revisões, artigos de opinião, estudos de vida real, e um RCT mais recente, suportam a conclusão de que o omalizumab é muito eficaz e possui um excelente perfil de segurança na UCE, com tempos de resposta habitualmente rápidos, embora variáveis. ${ }^{26,52,152-176} \mathrm{As}$ percentagens de doentes com controlo total dos sintomas sob omalizumab reportadas variam de $43,0 \%$ a $100,0 \%$ (embora este último seja um estudo de vida real com apenas sete doentes, referindo-se a um período limitado no tempo) e as de resposta parcial de $10,0 \%$ a $65,8 \% .^{52,159,162-}$ $165,169,172,174$

Os estudos publicados até à data sugerem que o perfil de eficácia e segurança não dependem de terapêuticas anteriores, ${ }^{177}$ nem da existência de evidência de autoimunidade subjacente, idade, género, ou valores séricos de lgE total. ${ }^{159}$

Por outro lado, em doentes que sofreram recidiva após descontinuação do tratamento - $58,3 \%$ no estudo de Ghazanfar et al/74 e $100 \%$ no estudo de Metz et al, dos quais $92 \%$ após duas a quatro semanas da descontinuação e $8 \%$ após 4 e 7 meses $^{178}$ - 67,4\% a $100 \%$ responderam totalmente ao re-tratamento com omalizumab. ${ }^{174,178}$ Dois estudos concluem que, na Holanda, o omalizumab é custo-efectivo comparado tanto com a ciclosporina como com até quatro vezes as doses diárias aprovadas de anti-H1, representando também uma opção terapêutica custo-efectiva para a UCE no Reino Unido. ${ }^{179}$ Embora o omalizumab esteja associado a um aumento de custos, este é baixo quando se considera o aumento de quality-adjusted life-years (QALY). ${ }^{180}$

Algumas questões mantêm-se em aberto em relação ao omalizumab na UCE, nomeadamente a duração ideal do tratamento, ${ }^{158,164,175,181}$ os intervalos entre as administrações, ${ }^{163} \mathrm{e}$ as doses ideais para cada doente, ${ }^{164}$ por forma a atingir o controlo completo dos sintomas. Os regimes de longa duração carecem ainda de mais investigação. ${ }^{26,158}$ Já existem, contudo, algumas propostas de algoritmos de tratamento com omalizumab para tentar responder as estas questões. ${ }^{52,155,156}$

Não existem comparações diretas entre o omalizumab e a ciclosporina, possivelmente dada a reconhecida dife- 
rença entre os perfis de segurança destes dois fármacos No entanto, das três comparações indiretas encontradas, dois estudos concluem que o omalizumab é superior à ciclosporina em eficácia, ${ }^{141,154}$ enquanto um conclui que a eficácia é semelhante, mas o perfil de segurança da ciclosporina é inferior. 153

Dada a evidência apresentada, nomeadamente o reconhecido pior perfil de segurança da ciclosporina, e o facto de esta ser de utilização off-label para a UCE, conduz a uma recomendação para utilizar preferencialmente omalizumab antes de considerar o tratamento com ciclosporina.

Recomendação: A ciclosporina é recomendada após ausência de resposta clínica ao omalizumab (LoE 1, GR A).

Pergunta 10: Relativamente à necessidade da reavaliação de continuação da terapêutica com omalizumab em doentes controlados (UAS7 $\leq 6$ ), concorda que esta seja feita a cada seis meses?

Não existe evidência direta do intervalo de tempo requerido ou desejável para a reavaliação de continuação da terapêutica com omalizumab em doentes com UCE controlada. As recomendações internacionais não mencionam este período. O RCM do omalizumab para UCE refere que 'a necessidade de continuação da terapêutica deve ser reavaliada periodicamente', e que, com base nos RCT existentes, a experiência clínica de terapêutica com omalizumab por períodos superiores a seis meses é limitada, ${ }^{182}$ havendo uma proposta de algoritmo terapêutico com omalizumab que se baseia na evolução do UAS7. ${ }^{155}$

Assim, e perante a falta de evidência científica, esta recomendação é baseada em evidência clínica.

Recomendação: Os doentes em tratamento com omalizumab devem ser reavaliados pelo menos a cada seis meses (LoE 5, GR D).

Pergunta 11: Relativamente à utilização de corticóides para o tratamento da UCE, concorda que estes sejam recomendados somente como tratamento de agudizações, num período máximo de 10 dias, e repetidos no máximo quatro vezes num ano?

Não existem RCT sobre a utilização de corticóides sistémicos na UCE, ${ }^{4,6}$ e os dados disponíveis são limitados. ${ }^{93}$ Uma análise retrospetiva de 750 doentes com UC refratária a anti-histamínicos reporta que a administração de corticóides orais durante 10 dias resultou na remissão de $50 \%$ dos doentes, ${ }^{30}$ mas um outro estudo retrospetivo em 641 doentes com UCE concluiu que o tempo necessário para controlar a doença não foi reduzido pela utilização de corticóides orais na abordagem terapêutica inicial. ${ }^{67}$ Embora o nível de evidência seja considerado baixo, e o grau de recomendação fraco, ${ }^{1}$ as várias recomendações e artigos de opinião de especialistas recomendam a utilização de corticóides apenas em agudizações, ${ }^{1-6,16,17,26,93,122,183}$ mas os tempos variam entre três e 10 dias, ${ }^{4,16,93}$ com 10 dias como máximo. ${ }^{2,5,16}$ Algumas recomendações referem apenas que o período de utilização dos corticóides deve ser curto, ${ }^{17,26,122}$ sem especificarem a duração. Numa das recomendações é referido que em alguns doentes poderão ser necessárias uma a três semanas para controlar os sintomas, ${ }^{6}$ e apenas uma revisão Canadiana refere que estes podem ser utilizados até um máximo de quatro semanas. ${ }^{3}$ Devido ao risco de efeitos adversos graves,,$^{1,2,6,93,122,183}$ a utilização a longo prazo de corticóides sistémicos é não recomendada, ${ }^{1,2,6,17,91,93,122,183}$ com elevado nível de evidência ${ }^{1}$ e grau de recomendação $A^{91} \mathrm{e}$, se eventualmente ocorrer, deve ser sempre sob supervisão de especialistas. ${ }^{1,91}$

Quanto à posologia de corticóides orais a curto prazo, as doses e regimes de descontinuação na UC são variáveis, abrangendo desde a redução progressiva de dose durante 10 dias até regimes complexos, com reduções de dose em dias alternados. ${ }^{17} \mathrm{Em}$ estudos com um número reduzido de doentes têm sido sugeridas doses entre 20 e $50 \mathrm{mg} / \mathrm{dia}$ de prednisolona ou equivalente ${ }^{1} ; 0,3-0,5 \mathrm{mg} /$ $\mathrm{kg} /$ dia de prednisona ou equivalente, seguido de reduções para metade da dose cada três a sete dias, durante um período máximo de duas a quatro semanas 3 ; 0,5 - 1,0 mg/ kg/ dia de prednisolona ou dose equivalente de outro corticóide oral, ${ }^{2,16}$ não sendo necessário desmame se for utilizado apenas durante $3-5$ dias $^{16} ; 1,0 \mathrm{mg} / \mathrm{kg}$ de prednisolona bid, até um máximo de $40 \mathrm{mg}$ por dia, durante 3 - 7 dias, iniciando desmame logo após o controlo da doença4; prednisona ou prednisolona até $1,0 \mathrm{mg} / \mathrm{kg} / \mathrm{dia}$, durante três a 10 dias, com desmame ${ }^{93}$; máximo de $10 \mathrm{mg} /$ dia ou 20 a $25 \mathrm{mg}$ cada dois dias, com desmame. ${ }^{183}$ Os dados publicados, referem recidivas de $47 \%,{ }^{184} 85,7 \%{ }^{53}$ e $40,7 \%{ }^{30}$ após suspensão de corticóides orais com desmame, mas são todos estudos pequenos, com casuísticas de 17, 21 e 86 doentes, respectivamente.

Quanto à necessidade de retomar ou prolongar o tratamento com corticóides por forma a manter a eficácia, não encontrámos dados publicados sobre o assunto.

Não havendo consenso, é nossa opinião que, quando se considera necessário utilizar corticóides orais, a dose não deverá ultrapassar $1,0 \mathrm{mg} / \mathrm{kg} / \mathrm{dia}$ de prednisolona ou dose equivalente de outro corticóide oral, até um máximo de 10 dias, incluindo a fase de desmame.

Finalmente, salientamos, mais uma vez, os graves efeitos adversos dos corticóides sistémicos, particularmente a longo prazo. ${ }^{185}$

Recomendação: Dado os reconhecidos efeitos adversos dos corticóides sistémicos a longo prazo, a sua utilização deverá ser reservada para o tratamento de agudizações, e durante o menor período de tempo possível (LoE 4, GR D).

\section{Pergunta 12: Quais são as indicações terapêuticas nas populações especiais?}

A maioria das recomendações sugere a utilização do mesmo algoritmo terapêutico em populações pediátricas, grávidas, mulheres a amamentar e idosos, sempre considerando a razão risco/benefício individual caso-a-caso. ${ }^{1,2,4,17}$ Há poucos estudos nestas populações especiais para qualquer dos fármacos incluídos nas recomendações 
Europeias.

Em idade pediátrica, um pequeno estudo com levocetirizina gotas orais em crianças com rinite alérgica ou UCE mostrou que doses de 1,25 mg/ dia qd e 1,25 mg/ dia bid eram eficazes e bem toleradas em crianças entre os seis e os 11 meses e entre os um e dois anos de idade, respetivamente. ${ }^{186}$ Dois pequenos estudos em populações pediátricas com UCE refratária a doses aprovadas ou superiores de anti-histamínicos, num total de 23 doentes, com idades compreendidas entre os nove e os 18 anos, reportaram que a utilização de ciclosporina em baixas doses foi eficaz na remissão da UCE, entre poucos dias e três meses. As recidivas que ocorreram resolveram com nova terapia com ciclosporina. Nenhum dos estudos reporta efeitos adversos. ${ }^{187,188} \mathrm{~A}$ ciclosporina deverá restringir-se aos casos mais graves e apenas a considerar em centros especializados em UCE. ${ }^{4}$

Na gravidez, a administração de loratadina e cetirizina nas doses aprovadas pode ser considerada segura, com a loratadina a ser o anti-H1 de segunda geração a escoIher como primeira linha em mulheres grávidas, visto existirem dados de seguimento de mais de 5000 gravidezes. ${ }^{2,4}$ A dose a utilizar deverá ser a dose mínima eficaz. ${ }^{17} \mathrm{Em}$ relação aos outros anti-histamínicos $\mathrm{H} 1$ de segunda geração não existem estudos publicados, o que não implica necessariamente que sejam menos seguros. No entanto, é considerada boa prática clínica evitar qualquer tipo de medicação durante a gravidez, já que nenhum medicamento pode ser considerado completamente seguro. Assim, os anti-histamínicos deverão apenas ser utilizados se estritamente necessários, e quando o benefício para a progenitora supera os potenciais riscos para o feto. ${ }^{4}$

Nas mulheres a amamentar os anti-histamínicos deverão apenas ser utilizados quando o potencial benefício para a progenitora supera os potenciais riscos para a criança. 1,2,4,17 Sabe-se que vários anti-histamínicos são excretados em quantidades significativas no leite materno e, embora não sejam conhecidos efeitos perniciosos nas crianças, estes devem ser evitados, se possível. Se for considerado clinicamente necessário, a dose a utilizar deverá ser a dose mínima eficaz ${ }^{4,17}$ e durante o período de tempo mais curto possível ${ }^{4} \mathrm{~A}$ loratadina e a cetirizina deverão ser preferencialmente consideradas, pois parecem mais seguras, com níveis baixos encontrados no leite. ${ }^{4}$ Novamente, o facto de não existirem estudos publicados em relação aos outros anti-histamínicos $\mathrm{H} 1$ de segunda geração não implica necessariamente que sejam menos seguros. O omalizumab está aprovado apenas para idades superiores a 12 anos, mas estão reportados dois casos de controlo total da UCE com omalizumab $150 \mathrm{mg} / \mathrm{mês,} \mathrm{em} \mathrm{duas} \mathrm{crianças}$ com quatro e cinco anos de idade, ambas com UCE refractária à dose dupla de anti-histamínicos $\mathrm{H} 1$ de segunda geração. No momento da publicação destes casos, ambas as crianças continuavam em tratamento com $150 \mathrm{mg} / \mathrm{mês}$ há 3 a 11 meses, em remissão, e sem efeitos adversos. ${ }^{189}$ O Xolair Pregnancy Registry (EXPECT) $)^{190}$ estudou 188 mulheres grávidas sob tratamento com omalizumab (com indicação para asma) durante o primeiro trimestre da gravidez, e mostrou que não houve diferenças na frequência de anomalias fetais, comparados com outras populações de progenitoras asmáticas. Noventa e oito das crianças nascidas durante o EXPECT foram também expostas ao omalizumab através do leite materno, com uma exposição média de 5,4 meses, sem efeitos adversos aparentes. ${ }^{190}$ Não há dados de excreção do omalizumab no leite humano e os efeitos na criança amamentada são desconhecidos, pelo que o omalizumab apenas deve ser utilizado na gravidez e amamentação se os potenciais benefícios superarem os potenciais riscos. ${ }^{170}$ Está também reportado um caso de uma mulher com UCE grave com angioedema, dermatite atópica e asma, tratada continuamente com omalizumab abrangendo duas gravidezes consecutivas, com eficácia e segurança. ${ }^{191}$

Em populações idosas com UCE, normalmente com várias co-morbilidades e medicações concomitantes, a eficácia e segurança de opções terapêuticas que não anti-histamínicos $\mathrm{H} 1$ de segunda geração nas doses aprovadas, não foram avaliados. Assim, recomenda-se extrema precaução particularmente na utilização de corticóides e ciclosporina

\section{$1^{\text {a }}$ linha}

Anti-histamínico de $2^{\mathrm{a}}$ geração na dose aprovada (on-label)

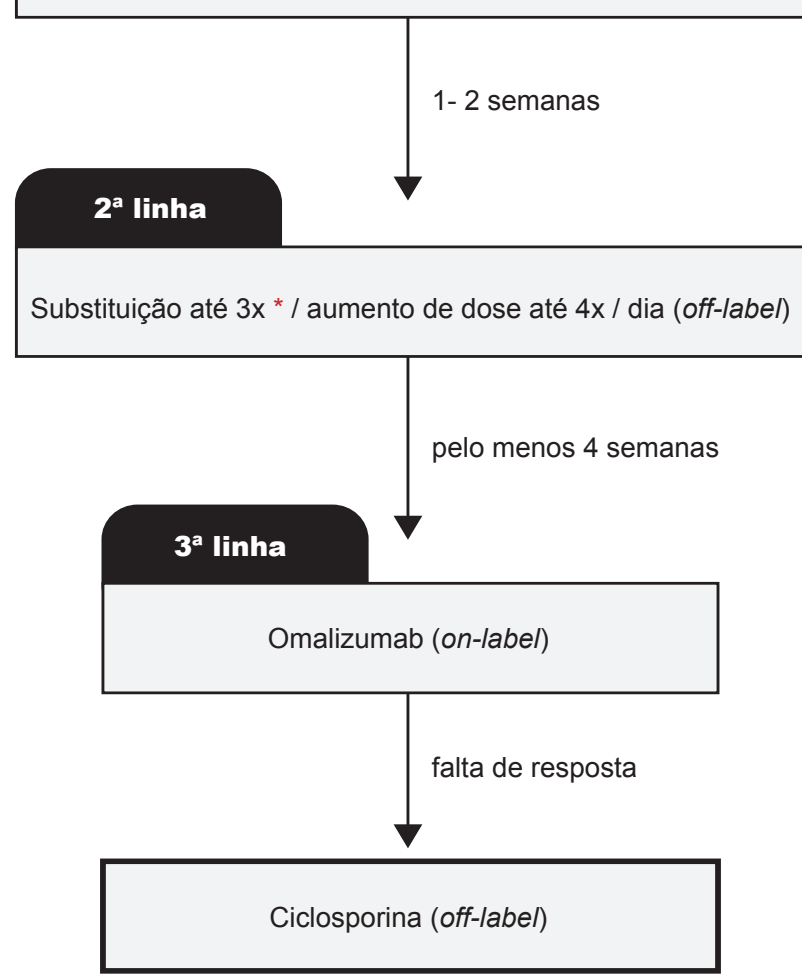

Nas exacerbações, e a qualquer momento, podem acrescentarse corticóides orais até 10 dias.

* on-label se antes de aumento de dose; off-label se depois.

Figura 2 - Proposta de algoritmo terapêutico para o tratamento da UCE em Portugal 
nestas populações. Também não há dados sobre aumento de dose dos anti-histamínicos $\mathrm{H} 1$ de segunda geração. ${ }^{192}$

Terminamos com a consideração de que, nestas populações especiais, poder-se-á equacionar a utilização off-label de qualquer dos medicamentos utilizados na UCE, tendo em especial atenção o perfil de segurança pois, nestes grupos concretos, a nossa grande preocupação, a par da eficácia, é a segurança.

Recomendação: Em populações especiais, apenas deverão ser utilizadas as indicações terapêuticas on-label, constantes da Tabela 4 (LoE 1, GR B). Poder-se-á considerar a utilização de terapêutica off-label, caso a caso, tendo em especial atenção o seu perfil de segurança (LoE 5, GR D).

\section{CONCLUSÃO E ALGORITMO TERAPÊUTICO}

Na sequência desta discussão alargada e votações no sentido de adaptar à realidade nacional as recomendações sobre o diagnóstico e tratamento da UCE propostas em 2014 pela European Academy of Allergy and Clinical Immunology (EAACI), Global Allergy and Asthma European Network (GA2LEN), European Dermatology Forum (EDF) e World Allergy Organization (WAO), propomos as recomendações nacionais para o diagnóstico e tratamento da UCE, estando o algoritmo terapêutico para o tratamento da UCE em Portugal resumido na Fig. 2.

Ressaltamos a necessidade de orientar os exames complementares de diagnóstico, para além do hemograma e VS e/ou PCR, apenas pela história clínica, evitando uma sobrecarga de exames que pouco acrescentam à orientação destes pacientes e, em relação ao tratamento, a recomendação de iniciar a escalada terapêutica pelos anti-H1 de segunda geração, nas doses terapêuticas recomendadas em AIM ou até $4 x$ essa dose diária, podendo haver substituição do anti-H1 de segunda geração até três vezes antes de passar ao degrau terapêutico seguinte, o omalizumab e, no caso de não resposta clínica, segue-se então a medicação com a ciclosporina A. Não se aconselha o uso de corticosteróides sistémicos a não ser em casos pontuais de exacerbações e por períodos inferiores a 10 dias.

\section{PERSPETIVAS FUTURAS}

A UCE tem um impacto significativo na qualidade de vida dos doentes que deveria ser melhorada. Há uma clara necessidade de um diagnóstico e tratamento precoces e corretos, de modo a minimizar os custos diretos e indiretos que esta patologia não controlada tem para os doentes e para a sociedade em geral. Por outro lado, é fundamental uma melhor compreensão dos mecanismos fisiopatológicos subjacentes a esta doença e, consequentemente, o desenvolvimento de métodos de diagnóstico mais específicos para a UCE. As terapêuticas atualmente existentes são eficazes na maioria dos casos de UCE, mas há muitos doentes refratários à terapêutica de primeira e segunda linha que têm escassas opções terapêuticas eficazes disponíveis. Dada a fraca qualidade e a baixa evidência científica da maioria dos trabalhos publicados na literatura, há muito por investigar nesta patologia, devendo os estudos futuros ser bem desenhados e controlados, de modo a melhorar a capacidade de diagnóstico etiológico e aumentar as opções terapêuticas eficazes disponíveis e aprovadas para estes doentes. Persiste ainda a necessidade de validar, para a população Portuguesa, outros instrumentos para a avaliação do controlo da urticária e do angioedema, tais como o Urticaria Control Test (UCT), o Angioedema Activity Score (AAS) e o Angioedema Quality of Life Questionnaire (AE-QoL). Estas recomendações serão revistas a cada dois anos, de modo a incorporar novos conhecimentos na abordagem diagnóstica e terapêutica da UCE.

\section{OBSERVAÇÕES}

Este artigo tem o apoio científico da Sociedade Portuguesa de Alergologia e Imunologia Clínica (SPAIC) e da Sociedade Portuguesa de Dermatologia e Venereologia (SPDV).

\section{REFERÊNCIAS}

1. Zuberbier T, Aberer W, Asero R, Bindslev-Jensen C, Brzoza Z, Canonica GW, et al. The EAACI/GA(2) LEN/EDF/WAO Guideline for the definition, classification, diagnosis, and management of urticaria: the 2013 revision and update. Allergy. 2014;69:868-87.

2. Wedi B, Wieczorek D, Raap U, Kapp A. Urticaria. J Dtsch Dermatol Ges. 2014;12:997-1007.

3. Sussman G, Hébert J, Gulliver W, Lynde C, Waserman S, Kanani A, et al. Insights and advances in chronic urticaria: a Canadian perspective. Allergy Asthma Clin Immunol. 2015;11:7.

4. Powell RJ, Leech SC, Till S, Huber PA, Nasser SM, Clark AT. BSACI guideline for the management of chronic urticaria and angioedema. Clin Exp Allergy. 2015;45:547-65.

5. Maurer M, Magerl M, Metz M, Zuberbier T. Revisions to the international guidelines on the diagnosis and therapy of chronic urticaria. J Dtsch Dermatol Ges. 2013;11:971-78.

6. Bernstein JA, Lang DM, Khan DA, Craig T, Dreyfus D, Hsieh F, et al. The diagnosis and management of acute and chronic urticaria: 2014 update. J Allergy Clin Immunol. 2014;133:1270-7.

7. Magerl M, Altrichter S, Borzova E, Giménez-Arnau A, Grattan CE, Lawlor $F$, et al. The definition, diagnostic testing, and management of chronic inducible urticarias - The EAACI/GA(2) LEN/EDF/UNEV consensus

recommendations 2016 update and revision. Allergy. 2016;71:780-802.

8. Saini SS. Basophil responsiveness in chronic urticaria. Curr Allergy Asthma Rep. 2009;9:286-90.

9. Kozel MM, Mekkes JR, Bossuyt PM, Bos JD. The effectiveness of a history-based diagnostic approach in chronic urticaria and angioedema. Arch Dermatol. 1998;134:1575-80.

10. Furue M, Yamazaki S, Jimbow K, Tsuchida T, Amagai M, Tanaka T, et al. Prevalence of dermatological disorders in Japan: a nationwide, crosssectional, seasonal, multicenter, hospital-based study. J Dermatol. 2011;38:310-20.

11. Zazzali JL, Broder MS, Chang E, Chiu MW, Hogan DJ. Cost, utilization, and patterns of medication use associated with chronic idiopathic urticaria. Ann Allergy Asthma Immunol. 2012;108:98-102.

12. Zuberbier T, Balke M, Worm M, Edenharter G, Maurer M. Epidemiology of urticaria: a representative cross-sectional population survey. Clin Exp Dermatol. 2010;35:869-73.

13. Gaig P, Olona M, Muñoz Lejarazu D, Caballero MT, Domínguez FJ, Echechipia S, et al. Epidemiology of urticaria in Spain. J Investig Allergo Clin Immunol. 2004;14:214-20.

14. Maurer M, Weller K, Bindslev-Jensen C, Giménez-Arnau A, Bousquet $\mathrm{PJ}$, Bousquet $\mathrm{J}$, et al. Unmet clinical needs in chronic spontaneous 
urticaria. A GA(2)LEN task force report. Allergy. 2011;66:317-30.

15. Carrasco J, Costa C, Gonçalo M, Guilherme M, Rodrigues Martins A. Qual é o impacto económico da Urticária Crónica Espontânea Grave em Portugal? A perspetiva do Serviço Nacional de Saúde e da Sociedade Portuguesa. Coimbra: SPAIC; 2015.

16. Termeer C, Staubach P, Kurzen H, Stromer K, Ostendorf R, Maurer M. Chronic spontaneous urticaria - a management pathway for patients with chronic spontaneous urticaria. J Dtsch Dermatol Ges. 2015;13:41928.

17. Ferrer M, Bartra J, Giménez-Arnau A, Jauregui I, Labrador-Horrillo M, Ortiz de Frutos J, et al. Management of urticaria: not too complicated, not too simple. Clin Exp Allergy. 2015;45:731-43.

18. Mitchell S, Balp MM, Samuel M, McBride D, Maurer M. Systematic review of treatments for chronic spontaneous urticaria with inadequate response to licensed first-line treatments. Int J Dermatol. 2015;54:1088104.

19. Stull D, McBride D, Georgiou P, Zuberbier T, Grattan C, Balp MM. Measuring patient severity in chronic spontaneous/idiopathic urticaria (CSU/CIU) as categorical health states: efficient and informative? Copenhagen: EAACI; 2014

20. Stull D, McBride D, Balp MM. Patient preferences for health: the value patients place on differential severity of chronic spontaneous (idiopathic) urticaria (CSU/CIU). Copenhagen: EAACl; 2014.

21. Weller K, Groffik A, Church MK, Hawro T, Krause K, Metz M, et al. Development and validation of the Urticaria Control Test: a patientreported outcome instrument for assessing urticaria control. J Allergy Clin Immunol. 2014;133:1365-72.

22. Jáuregui I, Ortiz de Frutos FJ, Ferrer M, Giménez-Arnau A, Sastre $\mathrm{J}$, Bartra J, et al. Assessment of severity and quality of life in chronic urticaria. J Investig Allergol Clin Immunol. 2014;24:80-6.

23. Mlynek A, Zalewska-Janowska A, Martus $P$, Staubach $P$, Zuberbier $\mathrm{T}$, Maurer M. How to assess disease activity in patients with chronic urticaria? Allergy. 2008;63:777-80.

24. Finlay AY, Khan GK. Dermatology Life Quality Index (DLQI)- a simple practical measure for routine clinical use. Clin Exp Dermatol. 1994;19:210-6.

25. Church DS, Church MK. Pharmacology of antihistamines. World Allergy Organ J. 2011;4:S22-7.

26. Maurer M, Vena GA, Cassano N, Zuberbier T. Current and future therapies for treating chronic spontaneous urticaria. Expert Opin Pharmacother. 2016;17:1131-9.

27. Resumo das Características do Medicamento. Ciclosporina. Aprovado por Infarmed 2012. [Consultado 2016 mar 09]. Disponível em: http:// www.infarmed.pt/infomed/download_ficheiro.php?med_id=35534\&tipo_ doc $=\mathrm{rcm}$.

28. OCEBM Levels of Evidence Working Group. The Oxford Levels of Evidence 2. Oxford Centre for Evidence-Based Medicine [Consultado 2016 fev 27]. Disponível em: http://www.cebm.net/index. aspx?o=56532011.

29. OCEBM Levels of Evidence Working Group. The Oxford Grades of Recommendation. Oxford Centre for Evidence-Based Medicine. [Consultado 2016 fev 27]. Disponível em: http://www.cebm.net/oxfordcentre-evidence-based-medicine-levels-evidence-march-2009/2009.

30. Asero R, Tedeschi A. Usefulness of a short course of oral prednisone in antihistamine-resistant chronic urticaria: a retrospective analysis. J Investig Allergol Clin Immunol. 2010;20:386-90.

31. Tarbox JA, Gutta RC, Radojicic C, Lang DM. Utility of routine laboratory testing in management of chronic urticaria/angioedema. Ann Allergy Asthma Immunol. 2011;107:239-43.

32. Krupashankar DS, Shashikala K, Madala R. Clinical and investigative assessment of patients with positive versus negative autologous serum skin test: a study of 80 South Indian patients. Indian J Dermatol. 2012;57:434-8.

33. Grattan CE, Dawn G, Gibbs S, Francis DM. Blood basophil numbers in chronic ordinary urticaria and healthy controls: diurnal variation, influence of loratadine and prednisolone and relationship to disease activity. Clin Exp Allergy. 2003;33:337-41.

34. Oliver ET, Sterba PM, Saini SS. Interval shifts in basophil measures correlate with disease activity in chronic spontaneous urticaria. Allergy. 2015;70:601-3

35. Magen E, Waitman DA, Dickstein Y, Davidovich V, Kahan NR. Clinicallaboratory characteristics of ANA-positive chronic idiopathic urticaria. Allergy Asthma Proc. 2015;36:138-44.

36. Ferrer M. Immunological events in chronic spontaneous urticaria. Clin Transl Allergy. 2015;5:30.

37. Lorenzo GD, Mansueto P, Melluso M, Candore G, Cigna D, Pellitteri ME, et al. Blood eosinophils and serum eosinophil cationic protein in patients with acute and chronic urticaria. Mediators Inflamm. 1996;5:113-5.

38. Lunge SB, Borkar M, Pande S. Correlation of serum antithyroid microsomal antibody and autologous serum skin test in patients with chronic idiopathic urticaria. Indian Dermatol Online J. 2015;6:248-52.

39. Jagodzinska J, Polaniak R, Birkner E, Kasperska-Zajac A. Analysis of circulating vascular endothelial growth factor and its soluble receptors in patients with different forms of chronic urticaria. Biomed Res Int. 2015;2015:578383.

40. Kasperska-Zajac A, Grzanka A, Jarzab J, Misiołek M, Wyszyńska-Chłap $\mathrm{M}$, Kasperski $\mathrm{J}$ et al. The association between platelet count and acute phase response in chronic spontaneous urticaria. Biomed Res Int. 2014;2014:650913.

41. Chandrashekar L, Rajappa M, Sundar I, Munisamy M, Ananthanarayanan $\mathrm{PH}$, Thappa DM, et al. Platelet activation in chronic urticaria and its correlation with disease severity. Platelets. 2014;25:162-5

42. Magen E, Mishal J, Zeldin Y, Feldman V, Kidon M, Schlesinger M, et al. Increased mean platelet volume and C-reactive protein levels in patients with chronic urticaria with a positive autologous serum skin test. Am J Med Sci. 2010;339:504-8

43. Tedeschi A, Asero R, Lorini M, Marzano AV, Cugno M. Plasma levels of matrix metalloproteinase- 9 in chronic urticaria patients correlate with disease severity and C-reactive protein but not with circulating histamine-releasing factors. Clin Exp Allergy. 2010;40:875-81.

44. Ucmak D, Akkurt M, Toprak G, Yesilova Y, Turan E, Yildiz I. Determination of dermatology life quality index, and serum C-reactive protein and plasma interleukin-6 levels in patients with chronic urticaria. Postepy Dermatol Alergol. 2013;30:146-51.

45. Kasperska-Zajac A, Grzanka A, Machura E, Misiolek M, Mazur B Jochem J. Increased serum complement C3 and C4 concentrations and their relation to severity of chronic spontaneous urticaria and CRP concentration. J Inflamm. 2013;10:22.

46. Aleem S, Masood Q, Hassan I. Correlation of C-reactive protein levels with severity of chronic urticaria. Indian J Dermatol. 2014;59:636.

47. Rabelo-Filardi R, Daltro-Oliveira R, Campos RA. Parameters associated with chronic spontaneous urticaria duration and severity: a systematic review. Int Arch Allergy Immunol. 2013;161:197-204.

48. Baek YS, Jeon J, Kim JH, Oh CH. Severity of acute and chronic urticaria correlates with D-dimer level, but not C-reactive protein or total IgE. Clin Exp Dermatol. 2014;39:795-800.

49. Konstantinou GN, Asero R, Maurer M, Sabroe RA, Schmid-Grendelmeie $P$, Grattan CE. EAACI/GA(2)LEN task force consensus report: the autologous serum skin test in urticaria. Allergy. 2009;64:1256-68.

50. Krupa Shankar DS, Ramnane M, Rajouria EA. Etiological approach to chronic urticaria. Indian J Dermatol. 2010:55:33-8.

51. Staevska M, Popov TA, Kralimarkova T, Lazarova C, Kraeva S, Popova $D$, et al. The effectiveness of levocetirizine and desloratadine in up to 4 times conventional doses in difficult-to-treat urticaria. J Allergy Clin Immunol. 2010;125:676-82.

52. Metz M, Ohanyan T, Church MK, Maurer M. Omalizumab is an effective and rapidly acting therapy in difficult-to-treat chronic urticaria: a retrospective clinical analysis. J Dermatol Sci. 2014;73:57-62.

53. Asero R. Chronic unremitting urticaria: is the use of antihistamines above the licensed dose effective? A preliminary study of cetirizine at licensed and above-licensed doses. Clin Exp Dermatol. 2007;32:34-8.

54. Rojo-Gutierrez MI, Flores-Ruvalcaba CN, Mellado-Abrego J, CastilloNarvaez G, Ramirez-Rojo DP. Utilidad de los estudios en busca de autoinmunidad en pacientes con urticaria crónica espontánea. Rev Alerg Mex. 2015;62:175-81.

55. Guttman-Yassky E, Bergman R, Maor C, Mamorsky M, Pollack S Shahar E. The autologous serum skin test in a cohort of chronic idiopathic urticaria patients compared to respiratory allergy patients and healthy individuals. J Eur Acad Dermatol Venereol. 2007;21:35-9.

56. Erbagci Z. The leukotriene receptor antagonist montelukast in the treatment of chronic idiopathic urticaria: a single-blind, placebocontrolled, crossover clinical study. JAllergy Clin Immunol. 2002;110:4848.

57. Calamita Z, Pela Calamita AB. Chronic spontaneous urticaria: epidemiological characteristics focusing on the histocompatibility profile and presence of antibodies. Inflamm Allergy Drug Targets. 2013;12:811.

58. Costa C. Diagnóstico de urticária crónica autoimune: estudo de activação dos basófilos por citometria de fluxo. Lisboa: Faculdade de Medicina da Universidade de Lisboa; 2008.

59. Kim JE, Jung $\mathrm{KH}$, Cho $\mathrm{HH}$, Kang $\mathrm{H}$, Park YM, Park $\mathrm{HJ}$, et al. The significance of hypersensitivity to autologous sweat and serum in 
cholinergic urticaria: cholinergic urticaria may have different subtypes. Int J Dermatol. 2015;54:771-7.

60. Asero R, Tedeschi A, Lorini M. Autoreactivity is highly prevalent in patients with multiple intolerances to NSAIDs. Ann Allergy Asthma Immunol. 2002;88:468-72.

61. Caproni M, Volpi W, Giomi B, Cardinali C, Antiga E, Melani L, et al. Chronic idiopathic and chronic autoimmune urticaria: clinical and immunopathological features of 68 subjects. Acta Derm Venereol. 2004;84:288-90.

62. Magen E, Delgado JS. Helicobacter pylori and skin autoimmune diseases. World J Gastroenterol. 2014;20:1510-6.

63. Cribier BJ, Santinelli F, Schmitt C, Stoll-Keller F, Grosshans E. Chronic urticaria is not significantly associated with hepatitis C or hepatitis $G$ infection: a case-control study. Arch Dermatol. 1999;135:1335-9.

64. Dauden E, Jimenez-Alonso I, Garcia-Diez A. Helicobacter pylori and idiopathic chronic urticaria. Int J Dermatol. 2000;39:446-52.

65. Ojetti V, Armuzzi A, De Luca A, Nucera E, Franceschi F, Candelli M, et al. Helicobacter pylori infection affects eosinophilic cationic protein in the gastric juice of patients with idiopathic chronic urticaria. Int Arch Allergy Immunol. 2001;125:66-72.

66. Cribier B. Urticaria and hepatitis. Clin Rev Allergy Immunol. 2006;30:259.

67. Kim S, Baek S, Shin B, Yoon SY, Park SY, Lee T, et al. Influence of initial treatment modality on long-term control of chronic idiopathic urticaria. PloS one. 2013;8:e69345

68. Hellmig S, Troch K, Ott SJ, Schwarz T, Folsch UR. Role of helicobacter pylori infection in the treatment and outcome of chronic urticaria. Helicobacter. 2008;13:341-5

69. Shakouri A, Compalati E, Lang DM, Khan DA. Effectiveness of Helicobacter pylori eradication in chronic urticaria: evidence-based analysis using the Grading of Recommendations Assessment, Development, and Evaluation system. Curr Opin Allergy Clin Immunol. 2010;10:362-9

70. Wedi B, Raap U, Wieczorek D, Kapp A. Urticaria and infections. Allergy Asthma Clin Immunol. 2009;5:10.

71. Magen E, Mishal J. Possible benefit from treatment of Helicobacter pylori in antihistamine-resistant chronic urticaria. Clin Exp Dermatol. 2013;38:7-12.

72. Bastos J, Peleteiro B, Barros R, Alves L, Severo M, de Fátima Pina $M$, et al. Sociodemographic determinants of prevalence and incidence of Helicobacter pylori infection in Portuguese adults. Helicobacter. 2013;18:413-22.

73. Carvalhana SC, Leitao J, Alves AC, Bourbon M, Cortez-Pinto $H$. Hepatitis B and C prevalence in Portugal: disparity between the general population and high-risk groups. Eur J Gastroenterol Hepatol. 2016;28:640-4

74. Khan S, Lynch N. Efficacy of montelukast as added therapy in patients with chronic idiopathic urticaria. Inflamm Allergy Drug Targets. 2012;11:235-43

75. Kibsgaard L, Lefevre AC, Deleuran M, Vestergaard C. A case series study of eighty-five chronic spontaneous urticaria patients referred to a tertiary care center. Ann Dermatol. 2014;26:73-8.

76. Viswanathan RK, Biagtan MJ, Mathur SK. The role of autoimmune testing in chronic idiopathic urticaria. Ann Allergy Asthma Immunol. 2012;108:337-41.

77. Arbuckle MR, McClain MT, Rubertone MV, Scofield RH, Dennis GJ, James JA, et al. Development of autoantibodies before the clinical onset of systemic lupus erythematosus. N Engl J Med. 2003;349:1526-33.

78. Fernandez SA, Lobo AZ, Oliveira ZN, Fukumori LM, Prigo AM, Rivitti EA. Prevalence of antinuclear autoantibodies in the serum of normal blood dornors. Rev Hosp Clin Fac Med Sao Paulo. 2003;58:315-9.

79. Feibelmann TC, Goncalves FT, Daud MS, Jorge Ade S, Mantese SA, Jorge PT. Avaliação da associação entre doença auto-imune de tireóide e urticária crônica idiopática. Arq Bras Endocrinol Metabol. 2007:51:1077-83.

80. Leznoff A, Josse RG, Denburg J, Dolovich J. Association of chronic urticaria and angioedema with thyroid autoimmunity. Arch Dermatol. 1983;119:636-40.

81. Leznoff A, Sussman GL. Syndrome of idiopathic chronic urticaria and angioedema with thyroid autoimmunity: a study of 90 patients. J Allergy Clin Immunol. 1989;84:66-71.

82. Gangemi S, Saitta S, Lombardo G, Patafi M, Benvenga S. Serum thyroid autoantibodies in patients with idiopathic either acute or chronic urticaria. J Endocrinol Invest. 2009;32:107-10.

83. Najib U, Bajwa ZH, Ostro MG, Sheikh J. A retrospective review of clinical presentation, thyroid autoimmunity, laboratory characteristics, and therapies used in patients with chronic idiopathic urticaria. Ann Allergy Asthma Immunol. 2009;103:496-501.

84. Cebeci F, Tanrikut A, Topcu E, Onsun N, Kurtulmus N, Uras AR. Association between chronic urticaria and thyroid autoimmunity. Eur J Dermatol. 2006;16:402-5.

85. Altrichter S, Peter HJ, Pisarevskaja D, Metz M, Martus P, Maurer M. IgE mediated autoallergy against thyroid peroxidase--a novel pathomechanism of chronic spontaneous urticaria? PloS one. 2011;6:e14794.

86. Spencer CA, Takeuchi M, Kazarosyan M, Wang CC, Guttler RB, Singer $\mathrm{PA}$, et al. Serum thyroglobulin autoantibodies: prevalence, influence on serum thyroglobulin measurement, and prognostic significance in patients with differentiated thyroid carcinoma. J Clin Endocrinol Metab. 1998:83:1121-7.

87. Pan XF, Gu JQ, Shan ZY. The prevalence of thyroid autoimmunity in patients with urticaria: a systematic review and meta-analysis Endocrine. 2015;48:804-10.

88. Toubi E, Kessel A, Avshovich N, Bamberger E, Sabo E, Nusem D, et al. Clinical and laboratory parameters in predicting chronic urticaria duration: a prospective study of 139 patients. Allergy. 2004;59:869-73.

89. Hollander SM, Joo SS, Wedner HJ. Factors that predict the success of cyclosporine treatment for chronic urticaria. Ann Allergy Asthma Immunol. 2011;107:523-8.

90. Marzano AV, Tavecchio S, Venturini M, Sala R, Calzavara-Pinton P, Gattorno M. Urticarial vasculitis and urticarial autoinflammatory syndromes. G Ital Dermatol Venereol. 2015;150:41-50.

91. Grattan CE, Humphreys F. Guidelines for evaluation and management of urticaria in adults and children. Br J Dermatol. 2007;157:1116-23.

92. Thorn F, Celius H, Odegard T, Mandla R, Hexeberg E. Assessment of efficacy and impact on work productivity and attendance after a mandatory switch to generic second-generation antihistamines: results of a patient survey in Norway. Clin Mol Allergy. 2011;9:5.

93. Schaefer P. Urticaria: evaluation and treatment. Am Fam Physician. 2011;83:1078-84

94. Ferrer M, Sastre J, Jáuregui I, Dávila I, Montoro J, del Cuvillo A, et al. Effect of antihistamine up-dosing in chronic urticaria. J Investig Allergol Clin Immunol. 2011;21:34-9.

95. Sanchez-Borges M, Caballero-Fonseca F, Capriles-Hulett A. Treatment of recalcitrant chronic urticaria with nonsedating antihistamines: is there evidence for updosing? J Investig Allergol Clin Immunol. 2013;23:141-4

96. Sanchez-Borges M, Ansotegui I, Jimenez JM, Rojo MI, Serrano C Yanez A. Comparative efficacy of non-sedating antihistamine updosing in patients with chronic urticaria. World Allergy Organ J. 2014;7:33.

97. Resumo das Características do Medicamento. Bilastina. Aprovado por Infarmed 2012. [Consultado 2016 mar 09]. Disponível em: http:// www.infarmed.pt/infomed/download_ficheiro.php?med_id=50275\&tipo_ doc $=\mathrm{rcm}$.

98. Resumo das Características do Medicamento. Cetirizina. Aprovado por Infarmed 2014. [Consultado 2016 mar 09]. Disponível em: http:// www.infarmed.pt/infomed/download ficheiro.php?med_id=41446\&tipo doc $=\mathrm{rcm}$

99. Kameyoshi Y, Tanaka T, Mihara S, Takahagi S, Niimi N, Hide M Increasing the dose of cetirizine may lead to better control of chronic idiopathic urticaria: an open study of 21 patients. $\mathrm{Br} \mathrm{J}$ Dermatol. 2007;157:803-4.

100. Resumo das Características do Medicamento. Desloratadina. Aprovado por Infarmed 2012. [Consultado 2016 mar 09]. Disponível em: http:// www.infarmed.pt/infomed/download_ficheiro.php?med_id=53577\&tipo doc $=\mathrm{rcm}$.

101.Resumo das Características do Medicamento. Ebastina. Aprovado por Infarmed 2013. [Consultado 2016 mar 09]. Disponível em: http:// www.infarmed.pt/infomed/download_ficheiro.php?med_id=29927\&tipo_ doc $=\mathrm{rcm}$

102. Godse KV. Ebastine in chronic spontaneous urticaria in higher doses Indian J Dermatol. 2011:56:597-8.

103. Resumo das Características do Medicamento. Fexofenadina. Aprovado por Infarmed 2011. [Consultado 2016 mar 09]. Disponível em: http:// www.infarmed.pt/infomed/download_ficheiro.php?med_id=8351\&tipo_ doc $=r c m$.

104. Finn Jr AF, Kaplan AP, Fretwell R, Qu R, Long J. A double-blind, placebocontrolled trial of fexofenadine $\mathrm{HCl}$ in the treatment of chronic idiopathic urticaria. J Allergy Clin Immunol. 1999;104:1071-8.

105. Nelson HS, Reynolds $\mathrm{R}$, Mason J. Fexofenadine $\mathrm{HCl}$ is safe and effective for treatment of chronic idiopathic urticaria. Ann Allergy Asthma Immunol. 2000;84:517-22.

106. Kawashima M, Harada S. Efficacy and safety of fexofenadine $\mathrm{HCl}$ in 
Japanese patients with chronic idiopathic urticaria. Int Arch Allergy Immunol. 2001;124:343-5.

107. Tanizaki H, Nakahigashi K, Miyachi Y, Kabashima K. Comparison of the efficacy of fexofenadine 120 and $240 \mathrm{mg} /$ day on chronic idiopathic urticaria and histamine-induced skin responses in Japanese populations. J Dermatolog Treat. 2013;24:477-80.

108. Resumo das Características do Medicamento. Levocetirizina. Aprovado por Infarmed 2009. [Consultado 2016 mar 09]. Disponível em: http:// www.infarmed.pt/infomed/download_ficheiro.php?med_id=47389\&tipo_ doc $=\mathrm{rcm}$

109. Godse KV. Updosing of antihistamines to improve control of chronic urticaria. Indian J Dermatol Venereol Leprol. 2010;76:61-2.

110. Resumo das Características do Medicamento. Loratadina. Aprovado por Infarmed 2015. [Consultado 2016 mar 09]. Disponível em: http:// www.infarmed.pt/infomed/download_ficheiro.php?med_id=1890\&tipo_ doc $=\mathrm{rcm}$.

111. Resumo das Características do Medicamento. Mizolastina. Aprovado por Infarmed 2010. [Consultado 2016 mar 09]. Disponível em: http:// www.infarmed.pt/infomed/download_ficheiro.php?med_id=5680\&tipo_ doc $=\mathrm{rcm}$.

112. Resumo das Características do Medicamento. Rupatadina. Aprovado por Infarmed 2014. [Consultado 2016 mar 09]. Disponível em: http:// www.infarmed.pt/infomed/download ficheiro.php?med_id=32877\&tipo doc $=\mathrm{rcm}$.

113. Dubertret L, Zalupca L, Cristodoulo T, Benea V, Medina I, Fantin S, et al. Once-daily rupatadine improves the symptoms of chronic idiopathic urticaria: a randomised, double-blind, placebo-controlled study. Eur J Dermatol. 2007;17:223-8.

114. Gimenez-Arnau A, Pujol RM, lanosi S, Kaszuba A, Malbran A, Poop $G$, et al. Rupatadine in the treatment of chronic idiopathic urticaria: a double-blind, randomized, placebo-controlled multicentre study. Allergy. 2007;62:539-46.

115. Resumo das Características do Medicamento. Cetirizina formulação pediátrica. Aprovado por Infarmed 2013. [Consultado 2016 mai 30]. Disponível em: http://www.infarmed.pt/infomed/download_ficheiro. php?med id =9532\&tipo_doc $=$ rcm.

116. Resumo das Características do Medicamento. Desloratadina formulação pediátrica. Aprovado por EMA 2006. [Consultado 2016 mai 30]. Disponível em: http://www.ema.europa.eu/docs/pt_PT/document library/EPAR_-_Product_Information/human/000313/WC500025540. pdf.

117. Resumo das Características do Medicamento. Ebastina formulação pediátrica. Aprovado por Infarmed 2013. [Consultado 2016 mai 30]. Disponível em: http://www.infarmed.pt/infomed/download_ficheiro. php?med_id=35020\&tipo_doc $=$ rcm.

118. Resumo das Características do Medicamento. Levocetirizina formulação pediátrica. Aprovado por Infarmed 2015. [Consultado 2016 mai 30]. Disponível em: http://www.infarmed.pt/infomed/download_ficheiro. php?med_id=41217\&tipo_doc=rcm.

119. Resumo das Características do Medicamento. Loratadina formulação pediátrica. Aprovado por Infarmed 2008. [Consultado 2016 mai 30] Disponível em: http://www.infarmed.pt/infomed/download ficheiro. php?med_id=38206\&tipo_doc=rcm.

120. Resumo das Características do Medicamento. Rupatadina formulação pediátrica. Aprovado por Infarmed 2014. [Consultado 2016 mai 30]. Disponível em: http://www.infarmed.pt/infomed/download ficheiro. php?med_id=55567\&tipo_doc=rcm.

121. Weller K, Ziege C, Staubach P, Brockow K, Siebenhaar F, Krause K et al. $\mathrm{H} 1$-antihistamine up-dosing in chronic spontaneous urticaria: patients' perspective of effectiveness and side effects--a retrospective survey study. PloS one. 2011;6:e23931.

122. Zuberbier T. Pharmacological rationale for the treatment of chronic urticaria with second-generation non-sedating antihistamines at higherthan-standard doses. J Eur Acad Dermatol Venereol. 2012;26:9-18.

123. Staevska M, Gugutkova M, Lazarova C, Kralimarkova T, Dimitrov V, Zuberbier T, et al. Night-time sedating $\mathrm{H} 1$ - antihistamine increases daytime somnolence but not treatment efficacy in chronic spontaneous urticaria: a randomized controlled trial. Br J Dermatol. 2014;171:148-54.

124. Nettis E, Colanardi MC, Paradiso MT, Ferrannini A. Desloratadine in combination with montelukast in the treatment of chronic urticaria: a randomized, double-blind, placebo-controlled study. Clin Exp Allergy. 2004;34:1401-7.

125. Di Lorenzo G, Pacor ML, Mansueto P, Esposito Pellitteri M, Lo Bianco C, Ditta V, et al. Randomized placebo-controlled trial comparing desloratadine and montelukast in monotherapy and desloratadine plus montelukast in combined therapy for chronic idiopathic urticaria. The
Journal of allergy and clinical immunology. Sep 2004;114(3):619-625.

126. Kosnik M, Subic T. Add-on montelukast in antihistamine-resistant chronic idiopathic urticaria. Respiratory medicine. Oct 2011;105 Suppl 1:S84-88.

127. Wan KS, Chang YS. Efficacy of leukotriene receptor antagonist with anti-H1 receptor antagonist plus anti-H2 receptor antagonist for treatment of refractory chronic idiopathic urticaria. J Allergy Clin Immunol. 2014;25:459-61.

128. Sanada S, Tanaka T, Kameyoshi Y, Hide M. The effectiveness of montelukast for the treatment of anti-histamine-resistant chronic urticaria. Arch Dermatol Res. 2005;297:134-8

129. Di Lorenzo G, Pacor ML, Mansueto P, Esposito-Pellitteri M, Ditta V, Lo Bianco $\mathrm{C}$, et al. Is there a role for antileukotrienes in urticaria? Clin Exp Dermatol. 2006;31:327-34.

130. de Silva NL, Damayanthi H, Rajapakse AC, Rodrigo C, Rajapakse S. Leukotriene receptor antagonists for chronic urticaria: a systematic review. Allergy Asthma Clin Immunol. 2014;10:24.

131.Di Lorenzo G, D’Alcamo A, Rizzo M, Leto-Barone MS, Bianco CL, Ditta $\mathrm{V}$, et al. Leukotriene receptor antagonists in monotherapy or in combination with antihistamines in the treatment of chronic urticaria: a systematic review. J Asthma Allergy. 2009;2:9-16.

132. Resumo das Características do Medicamento. Montelucaste. Aprovado por Infarmed 2015. [Consultado 2016 mar 09]. Disponível em: http:// www.infarmed.pt/infomed/download_ficheiro.php?med_id=7900\&tipo_ doc $=\mathrm{rcm}$.

133. Maurer M, Rosén K, Hsieh HJ, Saini S, Grattan C, Gimenéz-Arnau A, et al. Omalizumab for the treatment of chronic idiopathic or spontaneous urticaria. N Engl J Med. 2013;368:924-35.

134. Maurer M, Altrichter S, Bieber T, Biedermann T, Bräutigam M, Seyfried $S$, et al. Efficacy and safety of omalizumab in patients with chronic urticaria who exhibit $\lg \mathrm{E}$ against thyroperoxidase. J Allergy Clin Immunol. 2011;128:202-9.

135. Kaplan A, Ledford D, Ashby M, Canvin J, Zazzali JL, Conner E, et al. Omalizumab in patients with symptomatic chronic idiopathic/ spontaneous urticaria despite standard combination therapy. J Allergy Clin Immunol. 2013;132:101-9.

136. Saini SS, Bindslev-Jensen C, Maurer M, Grob JJ, Bülbül Baskan E, Bradley MS, et al. Efficacy and safety of omalizumab in patients with chronic idiopathic/spontaneous urticaria who remain symptomatic on H1 antihistamines: a randomized, placebo-controlled study. J Invest Dermatol. 2015;135:67-75.

137. Saini S, Rosen KE, Hsieh HJ, Wong DA, Conner E, Kaplan A, et al A randomized, placebo-controlled, dose-ranging study of singledose omalizumab in patients with $\mathrm{H} 1$-antihistamine-refractory chronic idiopathic urticaria. J Allergy Clin Immunol. 2011;128:567-73.

138. Kessel A, Toubi E. Low-dose cyclosporine is a good option for severe chronic urticaria. J Allergy Clin Immunol. 2009;123:970.

139.Di Gioacchino M, Di Stefano F, Cavallucci E, Verna N, Ramondo S, Paolini $F$, et al. Treatment of chronic idiopathic urticaria and positive autologous serum skin test with cyclosporine: clinical and immunological evaluation. Allergy Asthma Proc. 2003;24:285-90

140. Vena GA, Cassano N, Colombo D, Peruzzi E, Pigatto P. Cyclosporine in chronic idiopathic urticaria: a double-blind, randomized, placebocontrolled trial. J Am Acad Dermatol. 2006;55:705-9.

141. Savic S, Marsland A, McKay D, Ardern-Jones MR, Leslie T, Somenzi O, et al. Retrospective case note review of chronic spontaneous urticaria outcomes and adverse effects in patients treated with omalizumab or ciclosporin in UK secondary care. Allergy Asthma Clin Immunol. 2015;11:21.

142. Boubouka CD, Charissi C, Kouimintzis D, Kalogeromitros D Stavropoulos PG, Katsarou A. Treatment of autoimmune urticaria with low-dose cyclosporin A: A one-year follow-up. Acta Derm Venereol. 2011;91:50-4

143. Kessel A, Toubi E. Cyclosporine-A in severe chronic urticaria: the option for long-term therapy. Allergy. 2010;65:1478-82.

144. Grattan CE, O'Donnell BF, Francis DM, Niimi N, Barlow RJ, Seed PT, et al. Randomized double-blind study of cyclosporin in chronic 'idiopathic' urticaria. Br J Dermatol. 2000;143:365-72.

145. Loria MP, Dambra PP, D'Oronzio L, Nettis E, Pannofino A, Cavallo E, et al. Cyclosporin A in patients affected by chronic idiopathic urticaria: a therapeutic alternative. Immunopharmacol Immunotoxicol. 2001;23:20513.

146. Di Leo E, Nettis E, Aloia AM, Moschetta M, Carbonara M, Dammacco $\mathrm{F}$, et al. Cyclosporin-A efficacy in chronic idiopathic urticaria. Int $\mathrm{J}$ Immunopathol Pharmacol. 2011;24:195-200.

147. Serhat Inaloz H, Ozturk S, Akcali C, Kirtak N, Tarakcioglu M. Low- 
dose and short-term cyclosporine treatment in patients with chronic idiopathic urticaria: a clinical and immunological evaluation. J Dermatol. 2008;35:276-82.

148. Guaragna MA, Albanesi M, Stefani S, Franconi G, Di Stanislao C, Paparo Barbaro S. Chronic urticaria with high IgE levels: first results on oral cyclosporine A treatment. Clin Ter. 2013;164:115-8.

149. Baskan EB, Tunali S, Turker T, Saricaoglu H. Comparison of shortand long-term cyclosporine A therapy in chronic idiopathic urticaria. J Dermatolog Treat. 2004;15:164-8.

150. Trojan TD, Khan DA. Calcineurin inhibitors in chronic urticaria. Curr Opin Allergy Clin Immunol. 2012;12:412-20.

151. Urgert MC, van den Elzen MT, Knulst AC, Fedorowicz Z, van Zuuren EJ. Omalizumab in patients with chronic spontaneous urticaria: a systematic review and GRADE assessment. Br J Dermatol. 2015;173:404-15.

152. Marrouche N, Grattan C. Update and insights into treatment options for chronic spontaneous urticaria. Expert Rev Clin Immunol. 2014;10:397403.

153. Kaplan AP. Therapy of chronic urticaria: a simple, modern approach. Ann Allergy Asthma Immunol. 2014;112:419-25.

154.Zuberbier T, Maurer M. Omalizumab for the treatment of chronic urticaria. Expert Rev Clin Immunol. 2015;11:171-80.

155. Uysal P, Eller E, Mortz CG, Bindslev-Jensen C. An algorithm for treating chronic urticaria with omalizumab: dose interval should be individualized. J Allergy Clin Immunol. 2014;133:914-5.

156. Sussman G, Hébert J, Barron C, Bian J, Caron-Guay RM, Laflamme S, et al. Real-life experiences with omalizumab for the treatment of chronic urticaria. Ann Allergy Asthma Immunol. 2014;112:170-4.

157. Lang DM. Omalizumab is efficacious for management of recalcitrant, antihistamine-resistant chronic urticaria. Drugs Today. 2015;51:367-74.

158. Cooke A, Bulkhi A, Casale TB. Role of biologics in intractable urticaria. Biologics. 2015;9:25-33

159. Viswanathan RK, Moss MH, Mathur SK. Retrospective analysis of the efficacy of omalizumab in chronic refractory urticaria. Allergy Asthma Proc. 2013;34:446-52.

160.Stull DE, McBride D, Houghton K, Finlay AY, Gnanasakthy A, Balp MM. Assessing changes in chronic spontaneous/idiopathic urticaria: comparisons of patient-reported outcomes using latent growth modeling Adv Ther. 2016;33:214-24

161. Staubach P, Metz M, Chapman-Rothe N, Sieder C, Bräutigam M, Canvin $\mathrm{J}$, et al. Effect of omalizumab on angioedema in $\mathrm{H}$-antihistamine resistant chronic spontaneous urticaria patients: results from X-ACT, a randomised controlled trial. Allergy. 2016;71:1135-44.

162. Song CH, Stern S, Giruparajah M, Berlin N, Sussman GL. Long-term efficacy of fixed-dose omalizumab for patients with severe chronic spontaneous urticaria. Ann Allergy Asthma Immunol. 2013;110:113-7.

163. Silva PM, Costa AC, Mendes A, Barbosa MP. Long-term efficacy of omalizumab in seven patients with treatment-resistant chronic spontaneous urticaria. Allergol Immunopathol. 2015;43:168-73

164. Rottem M, Segal R, Kivity S, Shamshines L, Graif Y, Shalit M, et al. Omalizumab therapy for chronic spontaneous urticaria: the Israeli experience. Isr Med Assoc J. 2014;16:487-90.

165. Nam YH, Kim JH, Jin HJ, Hwang EK, Shin YS, Ye YM, et al. Effects of omalizumab treatment in patients with refractory chronic urticaria. Allergy Asthma Immunol Res. 2012;4:357-61.

166. McCormack PL. Omalizumab: a review of its use in patients with chronic spontaneous urticaria. Drugs. 2014;74:1693-9.

167. Lopez M, Navajas-Galimany L. What are the effects of omalizumab in refractory chronic spontaneous urticaria? Medwave. 2015;15:e6346.

168. Lefevre AC, Deleuran M, Vestergaard C. A long term case series study of the effect of omalizumab on chronic spontaneous urticaria. Ann Dermatol. 2013;25:242-5.

169. Labrador-Horrillo M, Valero A, Velasco M, Jáuregui I, Sastre J, Bartra J, et al. Efficacy of omalizumab in chronic spontaneous urticaria refractory to conventional therapy: analysis of 110 patients in real-life practice. Expert Opin Biol Ther. 2013:13:1225-8.

170. Labrador-Horrillo M, Ferrer M. Profile of omalizumab in the treatment of chronic spontaneous urticaria. Drug Des Devel Ther. 2015;9:4909-15.

171. Kaplan AP, Popov TA. Biologic agents and the therapy of chronic spontaneous urticaria. Curr Opin Allergy Clin Immunol. 2014;14:347-53.
172. Kaplan A, Ferrer M, Bernstein JA, Antonova E, Trzaskoma B, Raimundo $\mathrm{K}$, et al. Timing and duration of omalizumab response in patients with chronic idiopathic/spontaneous urticaria. J Allergy Clin Immunol. 2016;137:474-81.

173. Greenberger PA. Chronic urticaria: new management options. World Allergy Organ J. 2014;7:31

174. Ghazanfar MN, Sand C, Thomsen SF. Effectiveness and safety of omalizumab in chronic spontaneous or inducible urticaria: evaluation of 154 patients. Br J Dermatol. 2016;175:404-6

175. Carrillo DC, Borges MS, Garcia E, Egea E, Serrano CD. Omalizumab vs. placebo in the management of chronic idiopathic urticaria: a systematic review. World Allergy Organ J. 2014;7:72

176. Buyukozturk S, Gelincik A, Demirturk M, Kocaturk E, Colakoglu B, Dal M. Omalizumab markedly improves urticaria activity scores and quality of life scores in chronic spontaneous urticaria patients: a real life survey. J Dermatol. 2012;39:439-42.

177. Casale TB, Bernstein JA, Maurer M, Saini SS, Trzaskoma B, Chen H, et al. Similar efficacy with omalizumab in chronic idiopathic/spontaneous urticaria despite different background therapy. J Allergy Clin Immunol Pract. 2015;3:743-750

178. Metz M, Ohanyan T, Church MK, Maurer M. Retreatment with omalizumab results in rapid remission in chronic spontaneous and inducible urticaria. JAMA Dermatol. 2014;150:288-90.

179. Graham J, McBride D, Stull D, Halliday A, Alexopoulos ST, Balp M, et al. Cost-utility of omalizumab compared with standard of care for the treatment of chronic spontaneous urticaria (Csu). Value Health. 2015;18:A423

180. Graham J, McBride D, Stull D, Halliday A, Alexopoulos ST, Balp MM, et al. Cost utility of omalizumab compared with standard of care for the treatment of chronic spontaneous urticaria. Pharmacoeconomics. 2016;34:815-27.

181. Stitt JM, Dreskin SC. The potential role of omalizumab in the treatment of chronic urticaria. Immunotherapy. 2014;6:691-7.

182. Resumo das Características do Medicamento. Omalizumab. Aprovado por Infarmed 2009. [Consultado 2016 mar 09]. Disponível em: http:// www.ema.europa.eu/docs/pt_PT/document_library/EPAR - Product Information/human/000606/WC500057298.pdf.

183. Kaplan AP. What the first 10,000 patients with chronic urticaria have taught me: a personal journey. J Allergy Clin Immunol. 2009;123:713-7.

184. Augey F, Guillot-Pouget I, Gunera-Saad N, Berard F, Nicolas JF. Effe de l'arrêt des corticoïdes au cours de l'urticaire chronique (étude prospective de 17 malades). Ann Dermatol Venereol. 2008;135:21-5.

185. Resumo das Características do Medicamento. Prednisolona. Aprovado por Infarmed. 2008. [Consultado 2016 mar 30]. Disponível em: http:// www.infarmed.pt/infomed/download_ficheiro.php?med_id=24113\&tipo doc $=$ rcm.

186. Hampel F, Ratner P, Haeusler JM. Safety and tolerability of levocetirizine dihydrochloride in infants and children with allergic rhinitis or chronic urticaria. Allergy Asthma Proc. 2010;31:290-5.

187.Doshi DR, Weinberger MM. Experience with cyclosporine in children with chronic idiopathic urticaria. Pediatr Dermatol. 2009;26:409-13.

188. Neverman L, Weinberger M. Treatment of chronic urticaria in children with antihistamines and cyclosporine. J Allergy Clin Immunol Pract. 2014;2:434-8.

189. Netchiporouk E, Nguyen $\mathrm{CH}$, Thuraisingham T, Jafarian F, Maurer $\mathrm{M}$, Ben-Shoshan M. Management of pediatric chronic spontaneous and physical urticaria patients with omalizumab: case series. Pediatr Allergy Immunol. 2015;26:585-8.

190. Namazy J, Cabana MD, Scheuerle AE, Thorp JM Jr, Chen $H$ Carrigan G, et al. The Xolair Pregnancy Registry (EXPECT): the safety of omalizumab use during pregnancy. J Allergy Clin Immunol. 2015;135:407-12

191.Ghazanfar MN, Thomsen SF. Successful and safe treatment of chronic spontaneous urticaria with omalizumab in a woman during two consecutive pregnancies. Case Rep Med. 2015;2015:368053.

192. Ventura MT, Cassano N, Romita P, Vestita M, Foti C, Vena GA Management of chronic spontaneous urticaria in the elderly. Drugs Aging. 2015;32:271-82 